\title{
State-of-Charge-Based Droop Control for Stand-Alone AC Supply Systems with Distributed Energy Storage
}

\author{
Authors: Andoni Urtasun, Pablo Sanchis, and Luis Marroyo
}

The authors are from the Department of Electrical and Electronic Engineering, Public University of Navarra, Pamplona 31006, Spain (e-mail: andoni.urtasun@unavarra.es; pablo.sanchis@unavarra.es; luisma@unavarra.es).

Corresponding author: Andoni Urtasun, address: C/Arrosadia s/n, Planta Baja, 31006 (Pamplona, Spain), email: andoni.urtasun@unavarra.es, Phone: 0034948168934.

Abstract: The droop method is an advantageous technique for stand-alone AC supply systems, allowing for power sharing among various inverters with no need for communication cables. However, in stand-alone systems with multiple distributed energy storage units, the conventional droop methods are unable to control the storage unit state-of-charge (SOC) in order to change simultaneously. Existing techniques endeavor to solve this problem by changing the slope of the $P-f$ curve however this solution compromises the power response performance. As an alternative, this paper proposes a new SOC-based droop control, whereby the $P-f$ curve is shifted either upwards or downwards according to the battery SOC. The proposed technique makes it possible to select the time constant for the battery SOC convergence and, at the same time, to optimize the power response performance. The paper also shows how the SOC changes when the ratios between the battery capacity and the inverter rated power are different and how the proposed technique can limit the SOC imbalance. Simulation and experimental results corroborate the theoretical analysis.

Keywords: Batteries, distributed generation, droop control, energy management, microgrids, stand-alone system.

(C) 2015. This manuscript version is made available under the CC-BY-NC-ND 4.0 license http://creativecommons.org/licenses/by-nc-nd/4.0/ 


\section{INTRODUCTION}

For remote locations with difficult access to the power grid, stand-alone systems are more cost effective. In fact, these systems are widely established in mountainous regions and remote villages where they are used for a wide range of applications such as rural electrification, auxiliary power units for emergency services or military applications, and manufacturing facilities using sensitive electronics [1][3].

Distributed generation may be an attractive solution for stand-alone supply systems [4]-[7]. A frequently adopted and sustainable solution consists in installing photovoltaic (PV) and wind generation with battery energy storage [8]-[10]. Three configurations are currently in major use for this system: dc microgrids [11], hybrid ac/dc microgrids [12], [13], and ac microgrids [14]. Given that most loads are prepared for ac voltage, the ac configuration is probably the most frequently used at the moment. This configuration is shown in Fig. 1, where the wind turbines are connected to the ac grid through ac/ac converters whilst the batteries and PV generators are connected using dc/ac inverters [15], [16].

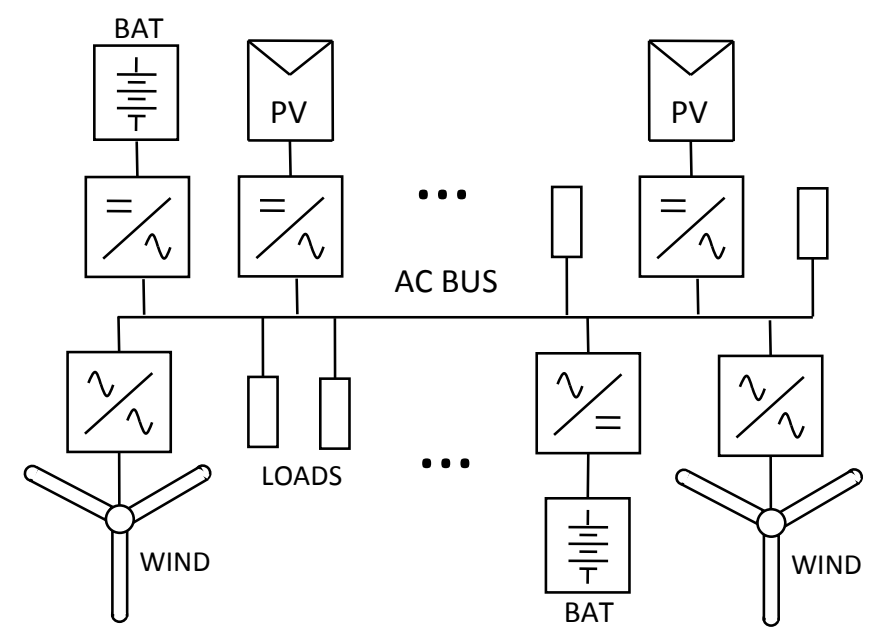

Fig. 1. Stand-alone hybrid system with distributed energy storage and generation

There are several techniques to implement the global control strategy in this system [17]. On one hand, there is a central control or master-slave approach where a supervisor sets in real time the operation point of each element [18]. The drawback of this approach is that requires a fast communication system between master and microgrid elements [19], [20]. Distributed control is another possible technique. In this case, the battery inverters operate as Voltage Source Inverters (VSI) using droop methods. This makes the inverters independent and avoids the need for communication between them, thereby reducing costs and improving reliability [21]-[24]. For their part, the photovoltaic/wind converters harvest the solar/wind energy and operate as Current Source Inverters (CSI) injecting power to the grid [25], [26]. These converters also operate locally since they perform Maximum Power Point Tracking (MPPT) during normal operation and can reduce their power depending on the grid frequency [25], [27], [28].

Thanks to the droop method, all battery inverters contribute to the grid generation. The real power control is based on the real power - frequency $P-f$ curve (or dc voltage - dc current $V_{d c}-I_{d c}$ curve in the case of dc microgrids). The $P-f$ curve slope is normally set according to the inverter rated power, in order to share the real powers in proportion to their ratings [29], [30]. Although the ratios between the battery capacity and the inverter rated power $\left(C / S_{\text {rat }}\right)$ should ideally be the same for all battery inverters to ensure that all battery state-of-charges (SOC) change simultaneously, in real applications this is not so. The initial $C / S_{\text {rat }}$ ratio will never be exactly the same for all battery inverters due to manufacturing variation or inadequate system sizing. Moreover, the battery aging will lead to a capacity reduction which will be more pronounced in some battery banks than in others. The initial SOC can also vary considerably from one battery to another. These situations cause the batteries to operate with different SOCs leading to less than optimal operation.

In [31], a fuzzy control is used for the storage energy control of electric-double-layer capacitors in dc microgrids. The fuzzy control changes the de voltage reference to balance the stored energy. Similarly, in [32], the control also modifies the dc voltage reference, in this case to balance the battery SOCs. 
However, these methods are not based on local measurements since information about the energy stored in the other units is required.

In order to maintain the same SOC for all energy storage units without the use of communication circuits, the $P-f\left(V_{d c}-I_{d c}\right)$ curve must be changed as a function of the SOC of each storage unit. Some authors have proposed changing the slope of this curve [26], [33]-[38]. In [33], it can be observed how the SOC of two batteries in an ac microgrid tends to reach the same value after a different initial SOC. However, the authors fail to analyze what occurs after that initial transient, when each battery inverter has a different $C / S_{\text {rat }}$ ratio. Furthermore, changing the $P-f$ curve slope has an effect on the stability and dynamic performance of the power response [39], [40]. This fact prevents the optimization of the power response and results in operating point-dependent damping and dynamics.

This paper proposes a new SOC-based droop control for stand-alone systems with distributed energy storage whereby the $P-f$ curve is shifted either upwards or downwards in line with the battery SOC. As a result, the battery with a higher SOC will either deliver more power or absorb less power until all the batteries reach the same SOC, with no need for communication circuits. Thanks to this curve shifting, the time constant for the battery SOC convergence can be set independently of the power response dynamics, unlike the slope changing method. The $P-f$ curve slope is kept constant, making it possible to optimize the power response performance and to achieve constant damping and dynamics. Furthermore, this method limits the SOC imbalance as required for batteries with different $C / S_{\text {rat }}$ ratios, without affecting the system stability.

The paper is organized as follows. Section 2 presents the modeling of the conventional droop method. Section 3 analyzes the SOC-based droop method which modifies the $P-f$ curve slope as a function of the SOC, hereinafter to be called the slope changing method. The power and SOC responses are first studied and then simulation results for a real power profile are presented. Section 4 analyzes the proposed SOCbased droop control, to be called the curve shifting method. Following a similar study to the slope changing method, both techniques are compared. Then, in section 5, the experimental results for the proposed method are shown. Finally, in section 6, some conclusions are drawn.

\section{CONVENTIONAL DROOP METHOD MODELING}

Fig. 2 represents the stand-alone system shown in Fig. 1, where the renewable-energy generators and loads are modeled together as a current source $i_{T}$ which demands real power $P_{T}$ and reactive power $Q_{T}$. The battery inverters are connected in parallel through the output impedance, formed by the filter inductance and the line impedance. Since the line impedance is much smaller than the filter impedance, the output impedance can be approximated as the filter inductance, $L_{i}$. The inverter rated powers $S_{r a t, i}$, battery capacities $C_{i}$, and instantaneous value of voltages and currents $e_{i}$ and $i_{i}$, are also defined in the figure.

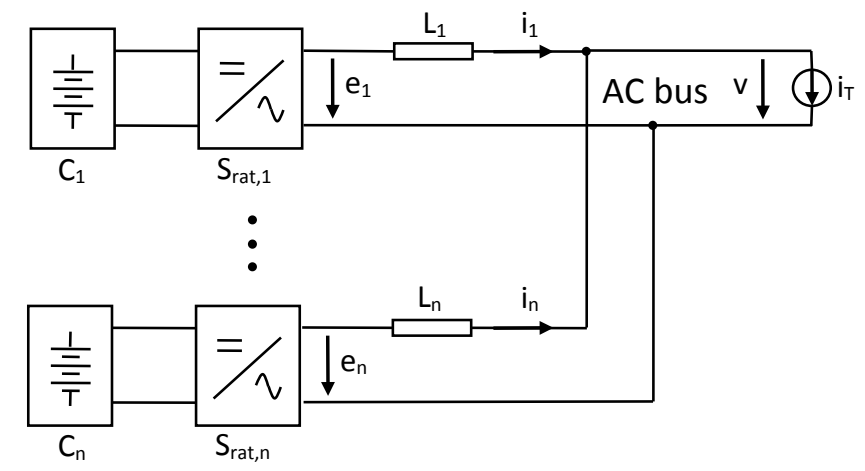

Fig. 2. Battery inverters connected in parallel

Each battery inverter will provide the following real power $P$ and reactive power $Q$ to the ac bus [41]:

$$
\begin{aligned}
& P=\frac{V E}{X} \cdot \sin \delta \\
& Q=\frac{V}{X}(E \cdot \cos \delta-V)
\end{aligned}
$$


where $E$ is the rms amplitude of the inverter output voltage, $\delta$ is the power angle, $V$ is the rms amplitude of the ac bus voltage and $X$ is the output reactance.

In practical applications, power angle $\delta$ is small. Thus, (1) and (2) can be rewritten as

$$
\begin{aligned}
& P=\frac{V E}{X} \cdot \delta \\
& Q=\frac{V}{X}(E-V) .
\end{aligned}
$$

Consequently, the real power of each inverter can be controlled by power angle $\delta$ and the reactive power can be regulated by means of output voltage $E$, which justifies the success of the conventional droop method. These equations, where the relationships $P-\delta$ and $Q-V$ are decoupled, are valid when the output impedance is mainly inductive, whereas in low voltage grids the line impedance is mainly resistive. However, in this paper, an rms voltage regulation is carried out instead of an instantaneous voltage regulation [4]. In doing so, the filter inductance also becomes part of the output impedance for the droop method. Given the high value of this filter impedance (the per-unit value is generally about $10 \%$ ), it is possible to consider the output impedance as inductive, regardless of the line impedance.

The line impedance also causes inaccuracy of reactive power control in the conventional droop method. In contrast, the real power control is not affected by line impedance since the steady-state frequency is the same in all points of the grid [42], [43]. As this paper focuses on the battery energy and therefore the real power, no further analysis is made of the reactive power droop method herein, however different droop methods can be consulted in [44], [45].

For the power response modeling, the dynamics of the battery and inverter loops are disregarded because their response is much faster than the inverter droop method response, as proved in [46]-[49]. The load power variation caused by voltage variations can also be neglected since the load impedance is always much higher than the inverter output impedance [50], [51]. The system model can then be obtained by applying (3) to the various battery inverters. For the sake of clarity, the model and technique are developed here for two battery inverters, and the model for $n$ battery inverters is included in the appendix. By means of (3), the influence of small variations in $E$ and $V$ on the real power can be disregarded. This approximation is reasonable since these voltages change but slightly in operation, making it possible to work on a linear model. Thus, it can be assumed that these values are constant and equal to their rated values. Taking account of these considerations and (3), the following is obtained:

$$
P_{1}=\frac{V E}{X_{1}} \cdot \delta_{1}, \quad P_{2}=\frac{V E}{X_{2}} \cdot \delta_{2} .
$$

The power angles are defined as

$$
\begin{aligned}
& \delta_{1}=\theta_{1}-\theta_{V}=\left(\theta_{i 1}+I \cdot f_{1}\right)-\theta_{V} \\
& \delta_{2}=\theta_{2}-\theta_{V}=\left(\theta_{i 2}+I \cdot f_{2}\right)-\theta_{V}
\end{aligned}
$$

where $\theta_{1}$ is the angle position of $e_{1}, \theta_{2}$ is the angle position of $e_{2}, \theta_{V}$ is the angle position of $v, \theta_{i l}$ is the initial angle position of $e_{1}, \theta_{i 2}$ is the initial angle position of $e_{2}, f_{1}$ is the frequency of $e_{1}, f_{2}$ is the frequency of $e_{2}$, and $\mathrm{I}=2 \pi / \mathrm{s}$ is the Laplace integrator.

The power balance at the point of common coupling is

$$
P_{1}+P_{2}=P_{T} .
$$

From (5)-(8), expressions for the system plant can be determined as

$$
\begin{gathered}
P_{1}=\frac{X_{2}}{X_{1}+X_{2}} P_{T}+\frac{V E}{X_{1}+X_{2}}\left(\theta_{i 1}-\theta_{i 2}\right)+\frac{V E}{X_{1}+X_{2}} I \cdot\left(f_{1}-f_{2}\right) \\
P_{2}=\frac{X_{1}}{X_{1}+X_{2}} P_{T}-\frac{V E}{X_{1}+X_{2}}\left(\theta_{i 1}-\theta_{i 2}\right)-\frac{V E}{X_{1}+X_{2}} I \cdot\left(f_{1}-f_{2}\right) .
\end{gathered}
$$

The conventional droop method changes $f_{1}$ and $f_{2}$ in order to equally share power $P_{T}$. The transfer functions of the droop control can be modeled as 


$$
\begin{aligned}
& f_{1}=f_{0}-m_{1} \cdot H_{P} \cdot P_{1} \\
& f_{2}=f_{0}-m_{2} \cdot H_{P} \cdot P_{2} \\
& H_{P}=\frac{1}{1+\tau_{P} S} \cdot \frac{1}{1+1.5 \cdot T_{S} \cdot s}
\end{aligned}
$$

where $f_{0}$ is the nominal frequency, $m_{1}$ and $m_{2}$ are the droop coefficients of the real power of inverter 1 and 2 , respectively, $\mathrm{H}_{\mathrm{P}}$ models the measurement and sampling of the power, $\tau_{P}$ is the time constant of the low-pass filter and $T_{S}$ is the sample time. The power measurement is based on the $p$ - $q$ theory in order to avoid $100 \mathrm{~Hz}$ oscillations and improve the dynamic performance [52]. The sampling approximation is useful since the crossover frequency of the open-loop gain is far enough from half the sampling frequency [53].

Introducing (11) and (12) in (9) and (10), expressions for the closed-loop powers are determined as

$$
\begin{aligned}
& P_{1}=\frac{V E \cdot I \cdot m_{2} \cdot H_{P}+X_{2}}{d e n_{P}} P_{T}+\frac{V E}{d e n_{P}}\left(\theta_{i 1}-\theta_{i 2}\right) \\
& P_{2}=\frac{V E \cdot I \cdot m_{1} \cdot H_{P}+X_{1}}{d e n_{P}} P_{T}-\frac{V E}{d e n_{P}}\left(\theta_{i 1}-\theta_{i 2}\right) \\
& \operatorname{den}_{P}=V E\left(m_{1}+m_{2}\right) \cdot I \cdot H_{P}+X_{1}+X_{2} .
\end{aligned}
$$

Taking into account that the $f_{l}=f_{2}$ after the power transient, the steady-state powers can be obtained from (8), (11) and (12) as

$$
P_{1}=\frac{m_{2}}{m_{1}+m_{2}} P_{T}, \quad P_{2}=\frac{m_{1}}{m_{1}+m_{2}} P_{T} .
$$

The objective of the droop method is that the inverters share the power in proportion to their ratings. From (17), this gives

$$
\frac{P_{1}}{S_{r a t 1}}=\frac{P_{2}}{S_{r a t 2}} \Rightarrow m_{1} \cdot S_{r a t 1}=m_{2} \cdot S_{r a t 2}=M_{P}
$$

where $M_{P}$ is the droop coefficient of the per-unit real power and has frequency units $(\mathrm{Hz})$.

Considering (18), coefficient $M_{P}$ is common for all inverters. The expression for the conventional droop control can now be rewritten as

$$
f=f_{0}-M_{P} \cdot p
$$

where $p=P / S_{\text {rat }}$ is the per-unit real power.

The closed-loop stability and transient response are determined by the closed-loop transfer function poles, that is by the roots of $d e n_{P}$ in (16). Hence, given certain system parameters, the choice of $M_{P}$ is important for the design of the power response in the conventional droop method. The root locus diagram for different $M_{P}$ values is shown in Fig. 3, and the system parameters are presented in Table 1. According to (16), the system has three poles although only the two dominant ones are shown in the figure. It can be observed that the system has first order dynamics for low $M_{P}$ values. Increasing $M_{P}$ makes the system less damped. Finally, from a certain $M_{P}$ value, the system becomes unstable. Equivalent results are obtained in other works [39], [46]. In this case, a good solution for parameter $M_{P}$ is $0.3 \mathrm{~Hz}$, which has been chosen as a trade-off between fast dynamics and a high stability margin. 
TABLE 1

SYSTEM PARAMETERS

\begin{tabular}{|c|c|}
\hline Nominal rms amplitude $E$ & $230 \mathrm{~V}$ \\
\hline Nominal rms amplitude $V$ & $230 \mathrm{~V}$ \\
\hline Battery 1 nominal capacity $C_{1}$ & $48 \mathrm{kWh}$ \\
\hline Battery 2 nominal capacity $C_{2}$ & $24 \mathrm{kWh}$ \\
\hline Battery 1 nominal voltage $V_{\text {bat } 1}$ & $120 \mathrm{~V}$ \\
\hline Battery 2 nominal voltage $V_{\text {bat } 2}$ & $60 \mathrm{~V}$ \\
\hline Inverter 1 rated power $S_{\text {rat } 1}$ & $6000 \mathrm{VA}$ \\
\hline Inverter 2 rated power $S_{\text {rat } 2}$ & $3000 \mathrm{VA}$ \\
\hline Inverter 1 output inductance $L_{1}$ & $3 \mathrm{mH}$ \\
\hline Inverter 2 output inductance $L_{2}$ & $4 \mathrm{mH}$ \\
\hline Time constant of the power filter $\tau_{P}$ & $20 \mathrm{~ms}$ \\
\hline Power sample time $T_{S}$ & $5 \mathrm{~ms}$ \\
\hline
\end{tabular}

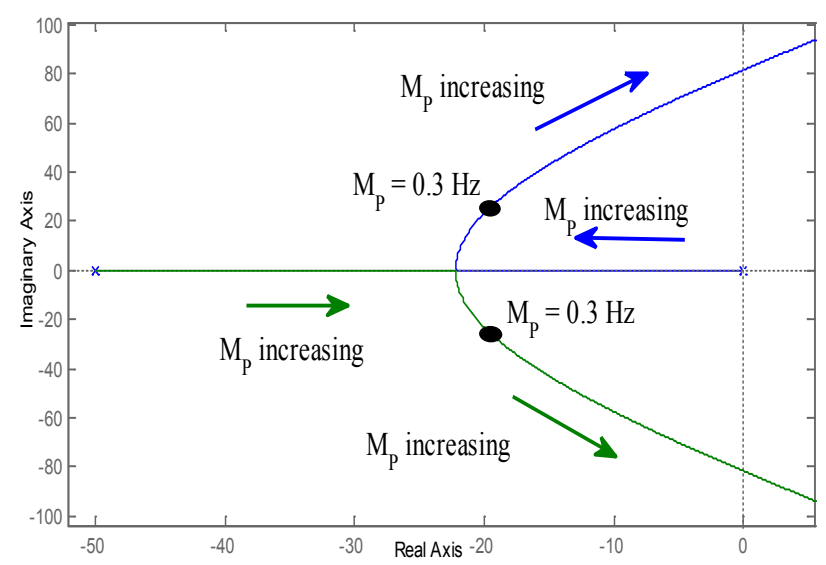

Fig. 3. Root locus diagram for the parameter $M_{P}$

\section{SLOPE CHANGING METHOD}

\subsection{Description}

As shown in section 2, the conventional droop method makes it possible to share the power between the battery inverters. However, the problem with this method is that the battery SOCs do not evolve simultaneously. For the purpose of balancing the battery SOCs without the use of communications, the $P-f$ curve must be changed as a function of each battery's SOC. From (19), two parameters can be used for this purpose, namely $f_{0}$ and $M_{P}$. The slope changing method, described in [33], proposes modifying the $P-f$ curve slope $M_{P}$. The curve proposed in [33] is chosen for the comparison because it represents a more general approach. This curve is expressed as follows:

$$
\begin{aligned}
& f=f_{0}-M_{P} \cdot p=f_{0}-\frac{M_{0}}{S O C^{n}} \cdot p, \quad p>0 \\
& f=f_{0}-M_{P} \cdot p=f_{0}-M_{0} \cdot S O C^{n} \cdot p, \quad p<0
\end{aligned}
$$

where $M_{0}$ is the droop coefficient for SOC $=1$, and $n$ is the SOC exponent $(n>0)$. Low $n$ values cause slope $M_{P}$ to vary slightly and, as a result, $M_{P}$ always remains similar to $M_{0}$. On the contrary, high $n$ values cause slope $M_{P}$ to change significantly for low SOCs and, as a result, $M_{P}$ reaches higher values than $M_{0}$ for $p>0$ and lower values than $M_{0}$ for $p<0$.

As an example, the $P-f$ curve is shown in Fig. 4 for $f_{0}=50 \mathrm{~Hz}, M_{0}=0.1 \mathrm{~Hz}, n=1$ and two batteries $\left(S O C_{1}=1\right.$ and $\left.S O C_{2}=0.5\right)$. It can be observed that for battery inverter $1, M_{P}=M_{0}=0.1 \mathrm{~Hz}$ when it is either supplying or absorbing power because $S O C_{I}=1$. However, for battery inverter $2, M_{P}=0.2 \mathrm{~Hz}>M_{0}$ when it is discharging and $M_{P}=0.05 \mathrm{~Hz}<M_{0}$ when it is charging. Two steady-state operating points for two frequencies $(49.94$ and $50.04 \mathrm{~Hz})$ are also shown in the figure. When the load demand is higher than generation $\left(P_{T}>0\right)$, both batteries discharge. It can be seen how inverter 1 supplies more per-unit power than inverter 2, thus helping balance the SOCs. On the other hand, when the generation is higher than the 
load demand $\left(P_{T}<0\right)$, both batteries charge. In this case, inverter 2 absorbs more per-unit power than inverter 1, which also helps balance the SOCs.

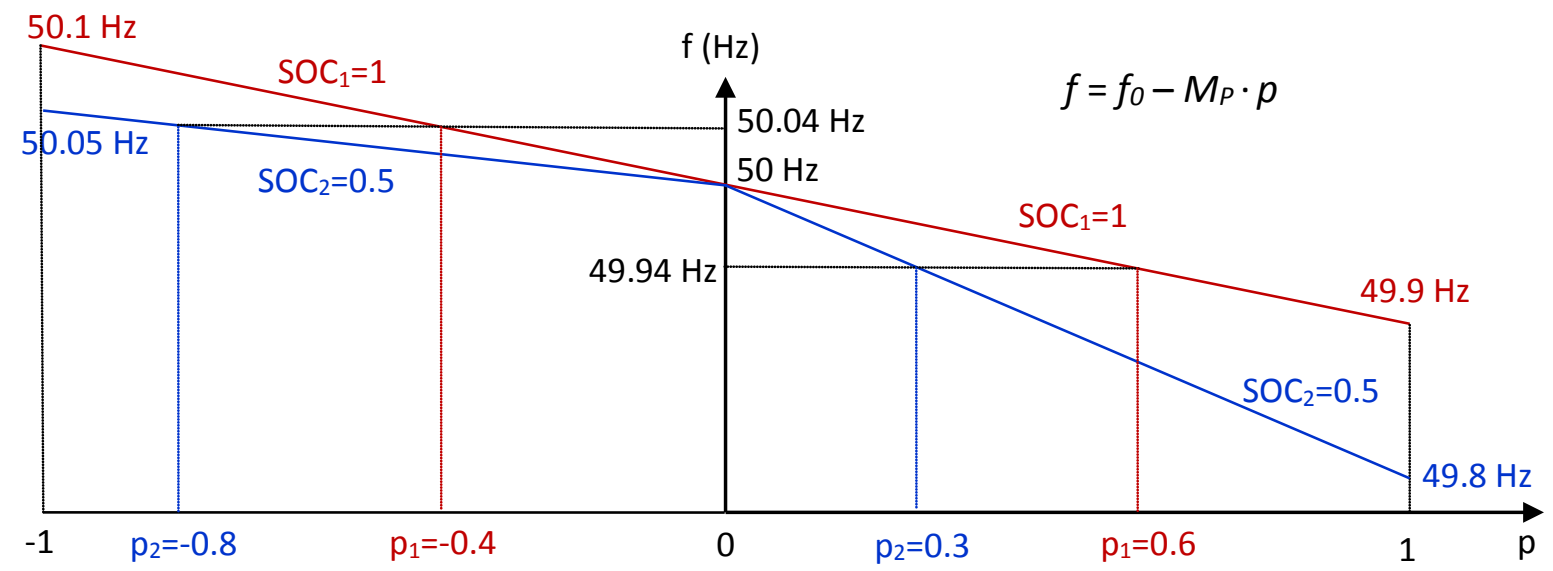

Fig. 4. $P-f$ curve for the slope changing method

The steady-state operating point can be easily obtained if it is considered that $f_{l}=f_{2}$ after the power transient. Equations (20) and (8) serve to obtain, for $P_{T}>0$,

$$
\begin{aligned}
& \frac{p_{1}}{p_{2}}=\left(\frac{S O C_{1}}{S O C_{2}}\right)^{n}, \quad p_{1}, p_{2}>0 \\
& P_{1}=\frac{S_{r a t 1} \cdot S O C_{1}^{n}}{S_{r a t 1} \cdot S O C_{1}^{n}+S_{r a t 2} \cdot S O C_{2}^{n}} \cdot P_{T}, \quad P_{T}>0 \\
& P_{2}=\frac{S_{r a t 2} \cdot S O C_{2}^{n}}{S_{r a t 1} \cdot S O C_{1}^{n}+S_{r a t 2} \cdot S O C_{2}^{n}} \cdot P_{T}, P_{T}>0 .
\end{aligned}
$$

Equation (22) shows that, using this method, the real power ratio depends on the ratio between the SOCs. The parameter $n$ increases $(n>1)$ or lowers $(n<1)$ the power ratio for the same SOC ratio.

Depending on the inverter power and the battery SOC, the grid frequency will have different values. The frequency will be lower than $f_{0}$ when the battery is delivering power and it will be higher than $f_{0}$ when the battery is absorbing power. The minimum frequency $f_{\min }$ is given for $\mathrm{SOC}=S O C_{\min }$ and $p=1$, whereas the maximum frequency $f_{\max }$ is found for $\mathrm{SOC}=S O C_{\max }=1$ and $p=-1$. The SOC is saturated to $S O C_{\min }=0.1$ to prevent $M_{P}$ from rising to a very large value. Using (20) and (21), the limit frequency values are then determined as

$$
f_{\min }=f_{0}-\frac{M_{0}}{0.1^{n}}, \quad f_{\max }=f_{0}+M_{0} .
$$

The slope changing method has two degrees of freedom for the design: $M_{0}$ and $n$. Careful consideration should be given to the selection of these parameters since they affect the frequency deviation, the power response performance and the SOC responsiveness. With regard to the frequency deviation, $f_{\min }$ can reach very low values, as shown in (25). However, this problem has already been solved in the literature by means of a secondary control which restores the frequency to its nominal value [33].

\subsection{Influence of $M_{0}$ and $n$ on the Power Response}

As shown in section 2 (see Fig. 3), droop method dynamics are highly dependent on the droop coefficient $M_{P}$. The slope changing method is based on modifying this coefficient in order to balance the SOCs. Consequently, this method results in variable power response performance. The slope variation range must then be restricted in order to prevent the system from a slow power response (low $M_{P}$ ) or instability (high $M_{P}$ ). According to (20) and (21), the maximum $M_{P}$ (charging side) and minimum $M_{P}$ (discharging side) can be found for $\mathrm{SOC}=S O C_{\min }=0.1$ as 


$$
M_{P \max }=\frac{M_{0}}{0.1^{n}}, \quad M_{P \min }=0.1^{n} \cdot M_{0} .
$$

A high $M_{P}$ value leads to a faster response and reduces the damping factor, which means that $M_{P \max }$ should be limited in order to guarantee a certain stability margin. In this paper, the minimum damping factor $\xi_{\min }$ has been taken as 0.2 , which determines the maximum slope $M_{P \max }$. The constraint $\xi \geq 0.2$ is very important since it is related to the system stability. Due to this constraint, one degree of freedom is already used and the slope changing method has now only one design parameter, namely parameter $n$.

Table 2 shows the power response parameters for different $n$ values for the system presented in Table 1. $M_{P \max }$ is set at $1 \mathrm{~Hz}$ due to the stability constraint. This value can be determined from the root locus of Fig. 3 for $\xi=0.2$. The remaining parameters depend on $n$. For a certain $n$ value, $M_{0}$ and $M_{P \min }$ can be obtained from (26). Parameter $\tau_{\min }$ is the power response time constant of the slowest operating point and is obtained from the root locus of Fig. 3 for $M_{P}=M_{P \min }$. As can be observed in Table 2, the power response becomes very slow for high $n$ values. The power distribution accuracy is another problem related to low $M_{P}$ values. In fact, errors in the frequency generated by the converter lead to important errors in the power distribution when $M_{P}$ is very low. This power error, referred to as $\Delta P_{\max \_\Delta f e r}$, is defined for the worst case, i.e. $S O C_{1}=S O C_{2}=S O C_{\text {min }}$, and its expression for a total frequency error $\Delta f_{\text {error }}=f_{\text {error } 1}+f_{\text {error } 2}$ can be obtained by means of (8) and (21) as

$$
\Delta P_{\text {max }_{-} \Delta \text { fer }}=\frac{2 \cdot S_{\text {rat1 } 1} \cdot S_{\text {rat } 2}}{S_{\text {rat } 1}+S_{\text {rat } 2}} \cdot \frac{\Delta f_{\text {error }}}{M_{P_{\min }}} .
$$

TABLE 2

POWER RESPONSE PARAMETERS FOR DIFFERENT N VALUES

\begin{tabular}{|c|c|c|c|c|c|c|}
\hline$n$ & $M_{P \max }$ & $M_{0}$ & $M_{P_{\min }}$ & $\xi_{\min }$ & $\tau_{\min }$ & $\Delta P_{\max }$ Afer \\
\hline 0.5 & $1 \mathrm{~Hz}$ & $0.32 \mathrm{~Hz}$ & $0.1 \mathrm{~Hz}$ & 0.2 & $0.10 \mathrm{~s}$ & $400 \mathrm{~W}$ \\
\hline 0.8 & $1 \mathrm{~Hz}$ & $0.16 \mathrm{~Hz}$ & $0.025 \mathrm{~Hz}$ & 0.2 & $0.50 \mathrm{~s}$ & $1592 \mathrm{~W}$ \\
\hline 1 & $1 \mathrm{~Hz}$ & $0.1 \mathrm{~Hz}$ & $0.01 \mathrm{~Hz}$ & 0.2 & $1.30 \mathrm{~s}$ & $4000 \mathrm{~W}$ \\
\hline 1.2 & $1 \mathrm{~Hz}$ & $0.063 \mathrm{~Hz}$ & $0.004 \mathrm{~Hz}$ & 0.2 & $3.28 \mathrm{~s}$ & $10000 \mathrm{~W}$ \\
\hline 1.5 & $1 \mathrm{~Hz}$ & $0.032 \mathrm{~Hz}$ & $0.001 \mathrm{~Hz}$ & 0.2 & $13.2 \mathrm{~s}$ & $40000 \mathrm{~W}$ \\
\hline
\end{tabular}

In Table 2, $\Delta P_{\max \_f f e r}$ is calculated for a frequency error $\Delta f_{\text {error }}=0.01 \mathrm{~Hz}$. As shown, it reaches very large values. The table also shows the strong influence of parameter $n$. For $n>1$, the power response becomes very slow and the power errors become very important for the worst operating conditions (with low SOCs and charging the batteries). From the power response point of view, it is therefore preferable to set low $n$ values. In so doing, slope $M_{P}$ would not vary too much and its value would always be close to the optimum one.

\subsection{Influence of $n$ on the SOC Response}

In order to analyze the influence of parameter $n$ on the SOC, a simple modeling for the SOC response is first developed. This will make it possible to determine the time constant for the SOC balancing as well as the SOC imbalance for different $C / S_{\text {rat }}$ ratios. Only the battery discharging will be shown here, as the battery charging analysis is similar and leads to the same conclusions.

The battery SOC can be calculated as

$$
S O C=S O C_{i}-\frac{1}{C_{A h}} \cdot \int i_{b a t} \cdot d t
$$

where $S O C_{i}$ is the initial SOC, $C_{A h}$ is the battery capacity in $\mathrm{Ah}$, and $i_{\text {bat }}$ is the battery output current. For a better SOC estimation, an enhanced coulomb counting method is used here [54]. Furthermore, in order to prevent long-term errors, the SOC is reset to $100 \%$ when the lead-acid battery operates at float voltage during a certain time, which is given by the manufacturer. This situation is frequent in stand-alone systems with no dispatchable units since the renewable generators must be oversized in order to reduce the loss of load probability [55].

Disregarding conversion losses and considering the battery voltage to be constant, (28) applied to the two batteries becomes

$$
S O C_{1}=S O C_{i 1}-\frac{1}{C_{1}} \cdot \int P_{1} \cdot d t
$$




$$
S O C_{2}=S O C_{i 2}-\frac{1}{C_{2}} \cdot \int P_{2} \cdot d t
$$

where $C_{1}$ and $C_{2}$ are the battery capacity in Wh.

Perturbing (29) and (30) and applying Laplace transform gives (small-signal variables are marked with a circumflex)

$$
S \hat{O} C_{1}=-\frac{\hat{P}_{1}}{C_{1} \cdot s}, \quad S \hat{O} C_{2}=-\frac{\hat{P}_{2}}{C_{2} \cdot s} .
$$

As the power response is much faster than the SOC response, it can be considered that the powers have reached their steady-state values and equations (22)-(24) are valid. The condition $f_{1}=f_{2}$ is thus also true, and by means of (20) it results in

$$
P_{1} \cdot S^{\prime} O C_{2}^{n} \cdot S_{\text {rat } 2}=P_{2} \cdot S O C_{1}^{n} \cdot S_{\text {rat } 1} .
$$

Perturbing (32) leads to

$$
n \cdot S O C_{2}^{n-1} \cdot P_{1} \cdot S_{\text {rat } 2} \cdot S \hat{O} C_{2}+S O C_{2}^{n} \cdot S_{\text {rat } 2} \cdot \hat{P}_{1}=n \cdot S O C_{1}^{n-1} \cdot P_{2} \cdot S_{\text {rat } 1} \cdot S \hat{O O} C_{1}+S O C_{1}^{n} \cdot S_{\text {rat } 1} \cdot \hat{P}_{2} .
$$

Then, introducing in this equation $\mathrm{SÔC}_{1}$ and $\mathrm{SÔC}_{2}$ expressions shown in (31), $P_{1}$ and $P_{2}$ expressions shown in (23) and (24), and $\hat{P}_{2}$ expression obtained from (8), the characteristic equation densoC for the SOC response is obtained as

$$
d e n_{S O C}=n \cdot P_{T} \cdot S_{\text {rat } 1} \cdot S_{\text {rat } 2}\left(\frac{S O C_{1}^{n} \cdot S O C_{2}^{n-1}}{C_{2}}+\frac{S O C_{1}^{n-1} \cdot S O C_{2}^{n}}{C_{1}}\right)+\left(S_{\text {rat } 1} \cdot S O C_{1}^{n}+S_{\text {rat } 2} \cdot S O C_{2}^{n}\right)^{2} \cdot s .
$$

The closed-loop transient response is determined by the roots of densoc. Since it is a first order equation with positive coefficients, the SOC response is always stable. The small-signal time constant $\tau_{S O C l}$ associated with the pole can be easily obtained from (34) as

$$
\tau_{S O C 1}=\frac{C_{1} \cdot C_{2} \cdot\left(S_{\text {rat } 1} \cdot S O C_{1}^{n}+S_{\text {rat } 2} \cdot S O C_{2}^{n}\right)^{2}}{n \cdot P_{T} \cdot S_{\text {rat } 1} \cdot S_{\text {rat } 2}\left(C_{1} \cdot S O C_{1}^{n} \cdot S O C_{2}^{n-1}+C_{2} \cdot S O C_{1}^{n-1} \cdot S O C_{2}^{n}\right)} .
$$

From (35), it can be stated that $\tau_{S O C I}$ depends both on some constant system parameters (battery capacities, inverter rated powers and parameter $n$ ) and some variables (the SOCs and the net power $P_{T}$ ). As a result, $\tau_{S O C l}$ varies during operation due to $S O C$ and $P_{T}$ variations. It is clear from (35) that the SOC response is faster for high values of net power $P_{T}$. The time constant $\tau_{S O C l}$ is represented in Fig. 5 as a function of $S O C_{1}$ for different $n$ values. In this figure, $S O C_{2}=0.5, P_{T}=4500 \mathrm{~W}$, and the system parameters are the ones presented in Table 1. It can be observed that the response is faster for low SOC values and for high $n$ values. In order to achieve a rapid SOC convergence, it is thus preferred to select a high value for parameter $n$, which contrasts with the low $n$ value preferred in terms of power response.

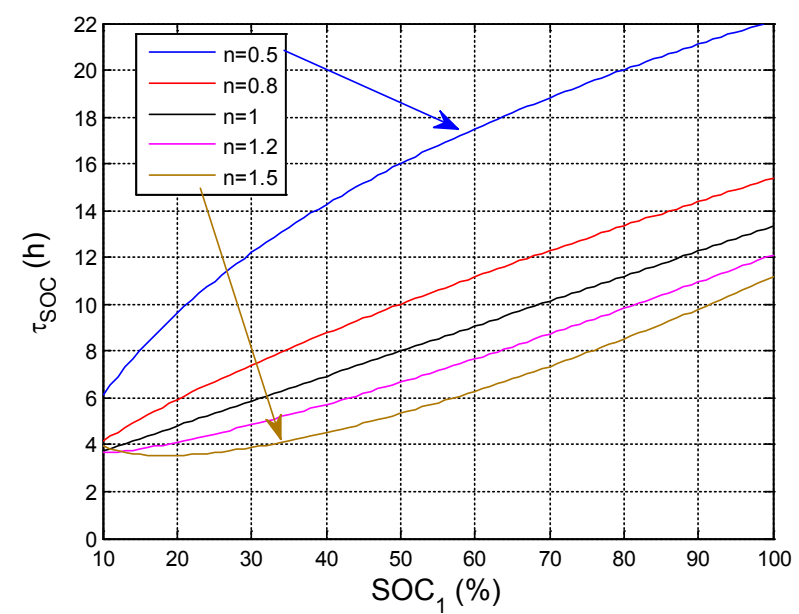

Fig. 5. Time constant $\tau_{S O C l}$ as a function of $S O C_{l}$ for different $n$ values 
The time constant $\tau_{S O C l}$ determines the transient response for a two-battery system with different initial SOCs. If the $C_{1} / S_{\text {ratl }}$ and $C_{2} / S_{\text {rat2 }}$ ratios are equal, then variations in the net power do not contribute to SOC imbalance and both SOCs remain equal after the initial transient. However, in real applications, the $C_{1} / S_{\text {rat } 1}$ and $C_{2} / S_{\text {rat } 2}$ ratios differ and it is not possible to keep both SOCs equal. This fact can be

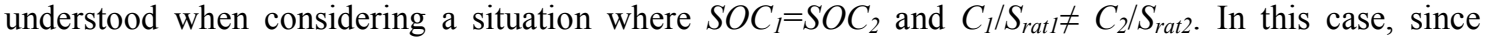
$S O C_{I}=S O C_{2}$, the control will cause $p_{1}=p_{2}$, as shown in (22). However, since $C_{1} / S_{\text {rat } 1} \neq C_{2} / S_{\text {rat } 2,} p_{1}=p_{2}$ will lead to an unequal SOC variation. This makes it necessary to analyze how net power variations contribute to SOC imbalance for different $C / S_{\text {rat }}$ ratios and how this can be limited.

Proceeding as indicated above, the expression for the small-signal difference $\mathrm{SO}_{1}-\mathrm{SO}_{2}$ can be determined as a function of the small signal net power. After an initial situation with $S O C_{i I} \neq S O C_{i 2}$, both SOCs will be similar thanks to the control. Thus, in order to obtain a clearer expression, it is considered that $S O C_{1}=S O C_{2}=S O C$. Using (8), (23), (24), (31) and (33) gives

$$
S \hat{O} C_{1}-S \hat{O} C_{2}=\frac{S_{r a t 1}+S_{r a t 2}}{C_{1}+C_{2}}\left(\frac{C_{1}}{S_{r a t 1}}-\frac{C_{2}}{S_{r a t 2}}\right) \cdot S O C \frac{\hat{P}_{T}}{n \cdot P_{T}\left(\tau_{S O C 1} \cdot s+1\right)} .
$$

From (36), it is obvious that when the $C_{1} / S_{\text {ratl }}$ and $C_{2} / S_{\text {rat2 }}$ ratios are equal, net power variations do not contribute to SOC imbalance. From (35) and (36), $P_{T}$ variations are best rejected for low SOCs, low $C / S_{\text {rat }}$ differences, high $n$ values, and high $P_{T}$. The influence of the $C / S_{\text {rat }}$ ratio, and parameter $n$ can be observed in Fig. 6, showing the bode diagram of small-signal SOC imbalance in front of the net power. The plot is carried out for the system presented in Table 1 and for an operating point with $S O C_{1}=S O C_{2}=0.5$ and $P_{T}=4500 \mathrm{~W}$. The curves are obtained for three different $n$ values $(n=0.5, n=1$ and $n=1.5)$ and assuming that battery 2 has a reduced capacity due to aging. More specifically, two families of curves are shown, one for $C_{2}=18 \mathrm{kWh}$ ( $25 \%$ of capacity loss) and another for $C_{2}=12 \mathrm{kWh}$ ( $50 \%$ of capacity loss). It can be observed in the figure that, for both cases, the SOC imbalance caused by the net power is lower for high $n$ values, which makes high $n$ values preferable to limit the SOC imbalance. Furthermore, it is worth mentioning that these curves are only valid for a certain operating point due to the small-signal modeling. Thus, the net power variation rejection will worsen for operating points with higher $S O C$ values and lower $P_{T}$ values.

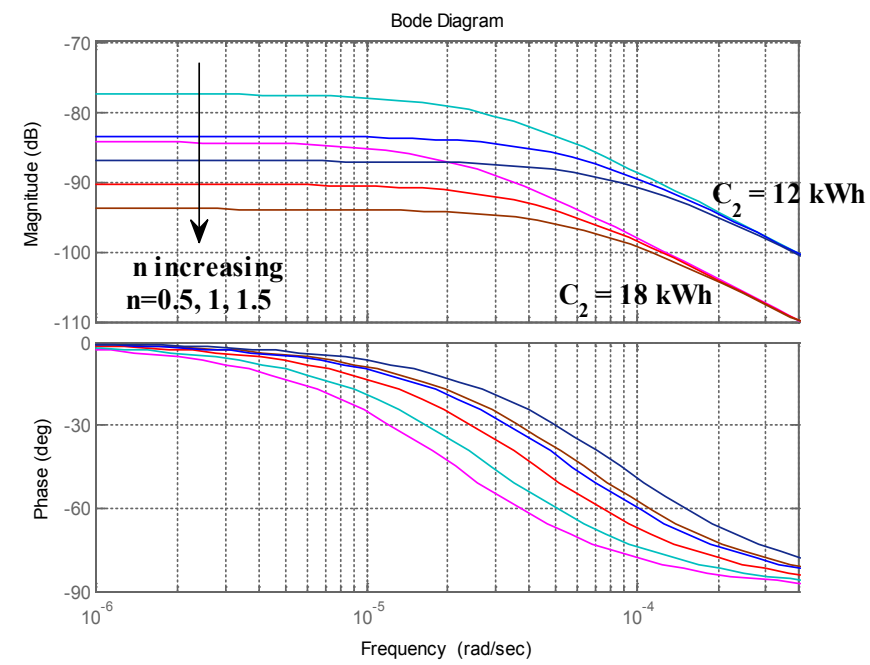

Fig. 6. Bode diagram of the SOC imbalance in front of the net power

\subsection{Simulation Results}

After analyzing the slope changing method in detail, it is then possible to select the two method parameters, namely $M_{0}$ and $n$. However, as shown in Table 2, $M_{0}$ is defined after selecting $n$ due to the stability constraint for the power response. As a result, our actual degree of freedom is parameter $n$.

As shown previously, the slope changing method does not decouple the power and SOC responses since changes in parameter $n$ have an effect on both. With regard to the real power, its response is optimized for a certain $M_{P}$ slope. It is then desirable to set a low $n$ value in order to make the $M_{P}$ slope slightly variable. Setting a high $n$ value causes a slow power response as well as power errors for some operating points. On the other hand, the SOC response is optimized for high $n$ values. This makes the response quicker and avoids high SOC imbalance in real systems. Therefore, it is impossible to simultaneously optimize the power and SOC responses and parameter $n$ needs to be chosen as a trade-off 
between both responses. Based on the previous analysis, parameter $n=1$ is selected for our system, resulting in $M_{0}=0.1 \mathrm{~Hz}$.

A one-year simulation is carried out for the system presented in Table 1 but with $C_{2}=18 \mathrm{kWh}(25 \%$ of capacity loss due to aging). The simulation is conducted with Simulink based on the model developed in this paper, using (23), (24), (29) and (30) for $P_{T}>0$, and the equivalent equations for $P_{T}<0$. When a battery is fully charged $(\mathrm{SOC}=1)$ and $P_{T}<0$, the generation is limited so that the battery does not absorb more power. The power profile $P_{T}$ is shown in Fig. 7 with values calculated every fifteen minutes and corresponding to measured data for consumption and generation from $1^{\text {st }}$ February 2009 to $31^{\text {th }}$ January 2010. The load profile was taken from two houses located in Pamplona, Spain, occupied by nine people in all. The PV and wind generation profiles were adapted from irradiance, cell temperature and wind speed data taken from the Public University of Navarra, in Pamplona, Spain, for a $10 \mathrm{kWp} \mathrm{PV} \mathrm{generator}$ and a $5 \mathrm{kWp}$ wind turbine. The generation and battery sizing for the stand-alone system is carried out based on [55].

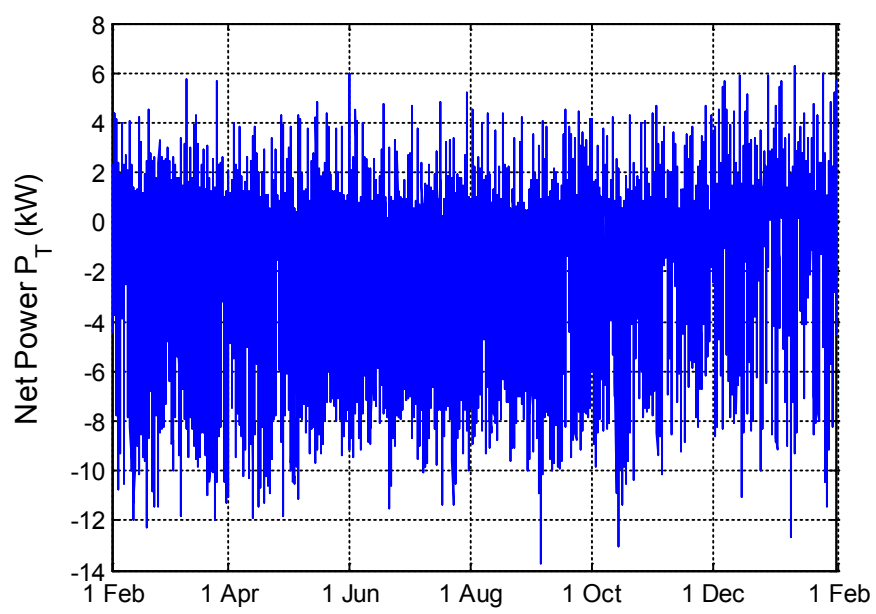

Fig. 7. One year net power profile $P_{T}$

Fig. 8 shows the simulation results for the system described with different initial SOCs, $S O C_{i I}=80 \%$ and $S O C_{i 2}=30 \%$. The transient SOC response is plotted in the first graph. It can be observed that, thanks to the control, both SOCs tend to adopt the same value. Moreover, it can be clearly seen that the smallsignal dynamics are highly variable, with a quicker response for high $P_{T}$ values, as predicted by (35). The second graph represents the entire one-year simulation, showing the SOC imbalance to be moderate. After the initial transient, the net power causes the SOC difference to change because $C_{1} / S_{\text {ratl }}=8 \mathrm{~h} \neq C_{2} / S_{\text {rat } 2}=6 \mathrm{~h}$, as predicted by (36). The $S O C_{1}-S O C_{2}$ difference during the one-year period, disregarding the initial transient, reaches a peak value of $-11.1 \%$, an rms value of $2.48 \%$ and an average value of $-0.65 \%$.
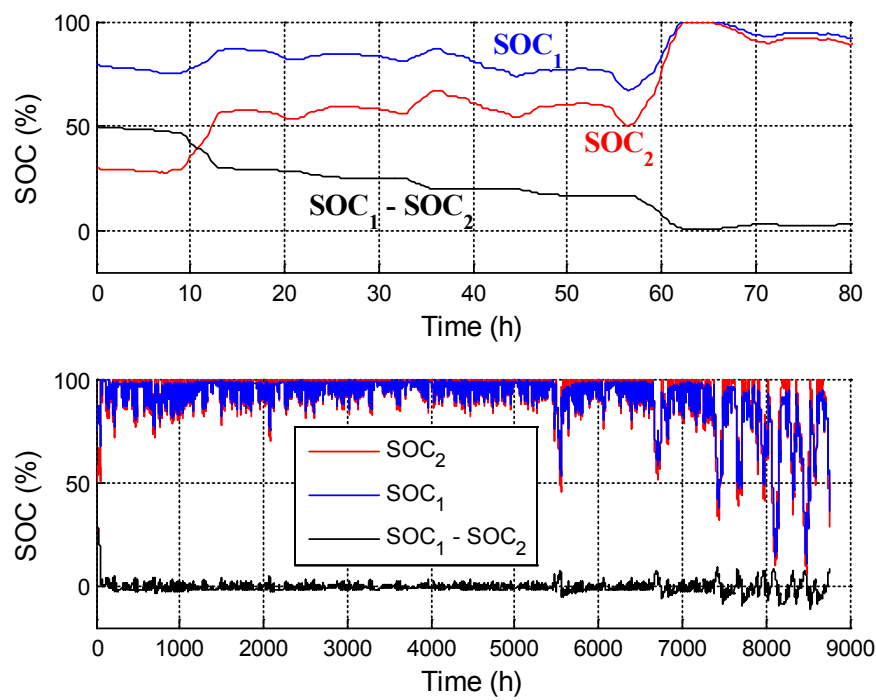

Fig. 8. SOC evolution for a stand-alone system for the slope changing method 


\section{CURVE SHIFTING METHOD}

\subsection{Description}

As presented above, the slope changing method changes parameter $M_{P}$ in (19) in order to balance the SOC. In contrast, the curve shifting method proposed herein modifies parameter $f_{0}$. This method shifts the $P-f$ curve either upwards or downwards depending on the battery SOC. The $P-f$ curve is expressed as follows:

$$
f=f_{0}-M_{P} \cdot p+M_{S} \cdot\left(S O C-S O C_{0}\right)
$$

where $M_{S}$ is the SOC coefficient and is the same for all inverters. Term $S O C_{0}$ makes it possible to define the desired SOC distribution between the batteries. In this paper, the control objective is $S O C_{1}=S O C_{2}$ and, for this purpose, $S O C_{10}=S O C_{20}=S O C_{0}$ is imposed. However, in some situations, an unequal SOC distribution can be desired, which can be readily achieved by setting different values for $S O C_{10}$ and $S O C_{20}$. In doing so, the control objective will become $S O C_{1}=S O C_{2}+S O C_{10}-S O C_{20}$. Furthermore, both the power and SOC dynamic responses will not be altered given that the term $M_{S} \cdot S O C_{0}$ is constant during operation.

The $P-f$ curve is shown in Fig. 9 for $f_{0}=50 \mathrm{~Hz}, M_{P}=0.3 \mathrm{~Hz}, M_{S}=0.3 \mathrm{~Hz}, S O C_{0}=0.8$ and two batteries $\left(S O C_{1}=1\right.$ and $\left.S O C_{2}=0.5\right)$. It can be observed that the curve for battery inverter 1 is shifted upwards in relation to the curve for battery inverter 2, although slope $M_{P}$ is constant. Two operating points are plotted in the figure, for $P_{T}>0$ and $P_{T}<0$. In both cases, $p_{1}$ is higher than $p_{2}$, making it possible to balance the SOCs.

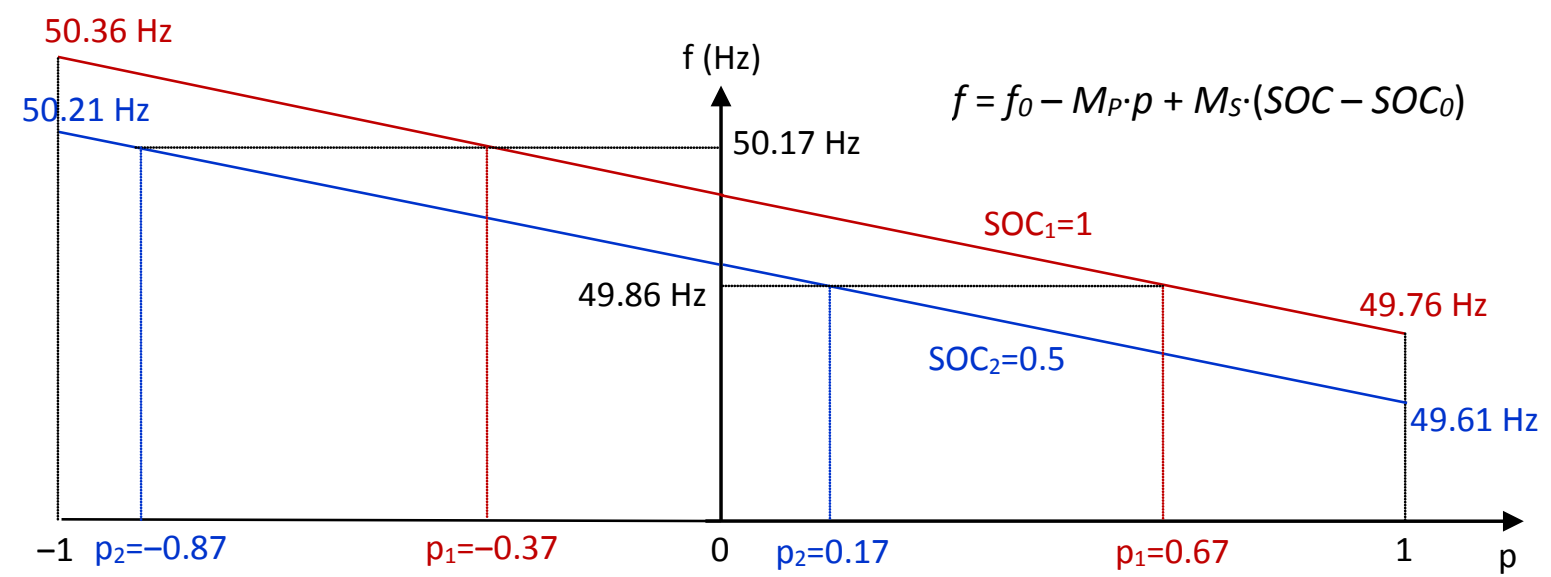

Fig. 9. $P-f$ curve for the curve shifting method

The steady-state power distribution can be determined by taking into account that $f_{l}=f_{2}$ after the power transient. Equations (37) and (8) give

$$
\begin{aligned}
& p_{1}-p_{2}=\frac{M_{S}}{M_{P}} \cdot\left(S O C_{1}-S O C_{2}\right) \\
& P_{1}=\frac{S_{r a t 1}}{S_{\text {rat } 1}+S_{\text {rat } 2}} \cdot P_{T}+\frac{S_{r a t 1} \cdot S_{\text {rat } 2}}{S_{r a t 1}+S_{r a t 2}} \frac{M_{S}}{M_{P}} \cdot\left(S O C_{1}-S O C_{2}\right) \\
& P_{2}=\frac{S_{\text {rat } 2}}{S_{\text {rat } 1}+S_{\text {rat } 2}} \cdot P_{T}-\frac{S_{\text {rat } 1} \cdot S_{\text {rat } 2}}{S_{\text {rat } 1}+S_{\text {rat } 2}} \frac{M_{S}}{M_{P}} \cdot\left(S O C_{1}-S O C_{2}\right) .
\end{aligned}
$$

From equation (38), it can be observed that the real power difference is proportional to the SOC difference, where quotient $M_{S} / M_{P}$ is the proportionality constant.

With this method, the grid frequency also varies in operation as a function of the inverter power and the battery SOC. The frequency reaches its minimum $f_{\min }$ value for $\mathrm{SOC}=S O C_{\min }=0.1$ and $p=1$, and its maximum value $f_{\max }$ for $\mathrm{SOC}=S O C_{\max }=1$ and $p=-1$.

$$
f_{\min }=f_{0}-M_{P}-M_{S} \cdot\left(S O C_{0}-0.1\right)
$$




$$
f_{\max }=f_{0}+M_{P}+M_{S} \cdot\left(1-S O C_{0}\right)
$$

The curve shifting method has two degrees of freedom for the design: $M_{P}$ and $M_{S}$. The selection of these parameters is important since they exert an influence on the frequency deviation, the power response performance and the SOC response performance. Thus, the power and SOC responses will be theoretically analyzed in this section in order to make a correct choice. With regard to the frequency deviation, the frequency variation obtained is low for a stand-alone system, except for very high $M_{P}$ and $M_{S}$ values. For example, with the parameters chosen for Fig. $9, f_{\min }=49.49 \mathrm{~Hz}$ and $f_{\max }=50.36 \mathrm{~Hz}$, which are allowable.

\subsection{Influence of $M_{P}$ and $M_{S}$ on the Power Response}

The model developed in section 2 is now used to determine the power response for the curve shifting method. The system plant was modeled by (9) and (10). For the control modeling, $H_{P}$ is added to (37) in order to account for the measurement and power sampling [see (13)], and the SOCs are considered as constant. The control then becomes

$$
\begin{aligned}
& f_{1}=f_{0}-m_{1} \cdot H_{P} \cdot P_{1}+M_{S} \cdot\left(S O C_{1}-S O C_{0}\right) \\
& f_{2}=f_{0}-m_{2} \cdot H_{P} \cdot P_{2}+M_{S} \cdot\left(S O C_{2}-S O C_{0}\right) .
\end{aligned}
$$

Inserting these equations into (9) and (10) leads to the closed-loop power expressions

$$
\begin{aligned}
& P_{1}=\frac{V E \cdot I \cdot m_{2} \cdot H_{P}+X_{2}}{\operatorname{den}_{P}} P_{T}+\frac{V E}{d e n_{P}}\left(\theta_{i 1}-\theta_{i 2}\right)+\frac{V E \cdot I \cdot M_{S}}{\operatorname{den}_{P}}\left(S O C_{1}-S O C_{2}\right) \\
& P_{2}=\frac{V E \cdot I \cdot m_{1} \cdot H_{P}+X_{1}}{\operatorname{den}_{P}} P_{T}-\frac{V E}{\operatorname{den}_{P}}\left(\theta_{i 1}-\theta_{i 2}\right)-\frac{V E \cdot I \cdot M_{S}}{\operatorname{den}_{P}}\left(S O C_{1}-S O C_{2}\right)
\end{aligned}
$$

where $\operatorname{den}_{P}$ was defined in (16).

It can be observed from (45) and (46) that the characteristic equation is the same as for the conventional droop method. As a result, the power response poles are also the same, as was to be expected since the $M_{P}$ slope is not changed by the curve shifting method. Since parameter $M_{S}$ does not appear in the expression of $d e n_{P}$, it does not affect the power response. The power response for this method has therefore been analyzed in section 2 by means of the $M_{P}$ root locus diagram shown in Fig. 3.

\subsection{Influence of $M_{P}$ and $M_{S}$ on the SOC Response}

Similarly to section 3.3, the time constant for the SOC response, and the SOC imbalance for different ratios $C / S_{\text {rat }}$ will be obtained here for a two-battery system. The model for an n-battery system is shown in the appendix. In this case, a small-signal analysis is not necessary since linear modeling is possible.

Applying Laplace transform to (29) and (30) gives

$$
S O C_{1}=S O C_{i 1}-\frac{P_{1}}{C_{1} \cdot s}, \quad S O C_{2}=S O C_{i 2}-\frac{P_{2}}{C_{2} \cdot s} .
$$

Accounting for power and SOC dynamics, it can be considered that the power steady-state has been reached and equations (38)-(40) are valid. By means of (8), (38) and (47), the expression for the SOC difference is obtained as

$$
\begin{aligned}
& S O C_{1}-S O C_{2}=\frac{M_{P}}{M_{S}} \frac{1}{C_{1}+C_{2}}\left(\frac{C_{1}}{S_{r a t 1}}-\frac{C_{2}}{S_{r a t 2}}\right) \cdot \frac{P_{T}}{\tau_{S O C 2} \cdot s+1}+\frac{\tau_{S O C 2} \cdot s}{\tau_{S O C 2} \cdot s+1}\left(S O C_{i 1}-S O C_{i 2}\right) \\
& \tau_{S O C 2}=\frac{M_{P}}{M_{S}} \cdot \frac{1 / S_{r a t 1}+1 / S_{r a t 2}}{1 / C_{1}+1 / C_{2}} .
\end{aligned}
$$

As shown in (48) and (49), the transfer function has only one pole, which has an associated time constant $\tau_{S O C 2}$. This parameter $\tau_{S O C 2}$ depends on the battery capacities, the inverter rated powers, and parameters $M_{P}$ and $M_{S}$; however, unlike the slope changing method, it does not vary in operation. In addition, its constant value can be set as desired by means of parameter $M_{S}$ once parameter $M_{P}$ has been selected for optimizing the power response. Increasing $M_{S}$ and thus the $M_{S} / M_{P}$ ratio makes the response faster. As an example, for the system presented in Table $1, M_{P}=0.3 \mathrm{~Hz}$ and $M_{S}=0.3 \mathrm{~Hz}, \tau_{S O C 2}=8$ hours is obtained. 
Once again from (48), it is possible to determine the influence of net power on the SOC imbalance for different $C / S_{\text {rat }}$ ratios, as performed in section 3.3. It should be noted that net power $P_{T}$ is best rejected for low $C / S_{\text {rat }}$ ratio difference and a high $M_{S} / M_{P}$ ratio. The bode diagram for the SOC imbalance in front of the net power is shown in Fig. 10, conducted for the system presented in Table 1. The curves are obtained for $M_{P}=0.3 \mathrm{~Hz}$, three different $M_{S}$ values $\left(M_{S}=0.1 \mathrm{~Hz}, M_{S}=0.3 \mathrm{~Hz}\right.$ and $\left.M_{S}=0.5 \mathrm{~Hz}\right)$ and assuming that battery 2 has lost part of its capacity due to aging. More specifically, two families of curves are shown, one for $C_{2}=18 \mathrm{kWh}$ ( $25 \%$ of capacity loss) and another for $C_{2}=12 \mathrm{kWh}$ ( $50 \%$ of capacity loss). Unlike the slope changing method, the linear modeling means that these curves are valid for every operating point. From the figure, it can be concluded that the SOC imbalance caused by the net power can be reduced by means of high $M_{S}$ values. Thus, since $M_{S}$ exerts no influence on the power response, it is possible to increase this parameter in order to limit the SOC imbalance.

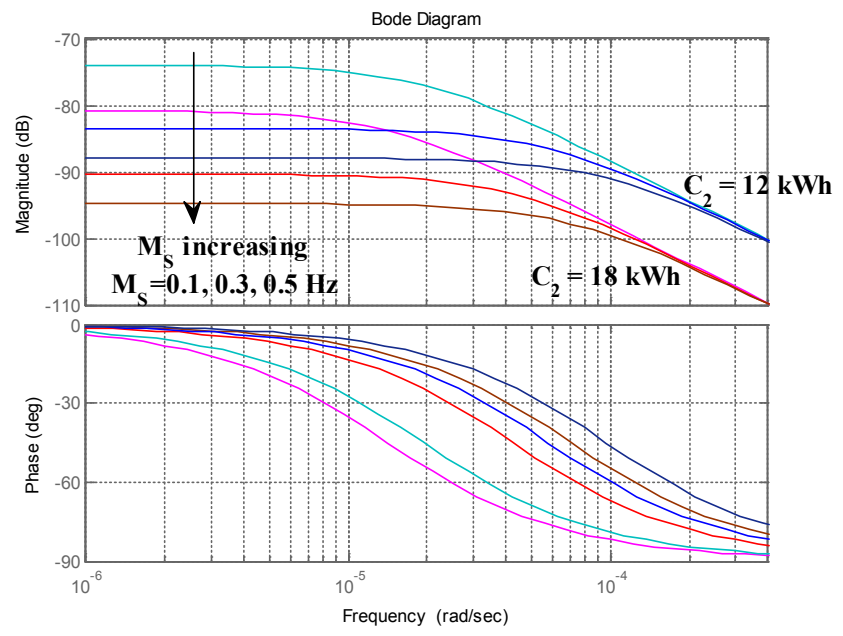

Fig. 10. Bode diagram of the SOC imbalance in front of the net power

\subsection{Simulation Results}

In this section, the curve shifting method parameters will first be selected. This method has two design degrees of freedom, namely the power droop coefficient $M_{P}$ and the SOC coefficient $M_{S}$.

As shown above, only the droop coefficient $M_{P}$ has an influence on the power transient. This parameter can thus be selected in order to optimize the power response, as was done in section 2. With regard to the SOC response, high values of the $M_{S} / M_{P}$ ratio reduce the transient time constant and prevents from high SOC imbalance in real systems. As a result, once parameter $M_{P}$ has been set for the power response, parameter $M_{S}$ can be selected in order to limit the SOC imbalance. Hence, the power and SOC responses can be independently designed by means of the proposed control. Based on the theoretical analysis, the parameter values selected are $M_{P}=0.3 \mathrm{~Hz}$ and $M_{S}=0.3 \mathrm{~Hz}$ for our system.

One-year simulation is also carried out here for the system presented in Table 1 but with $C_{2}=18 \mathrm{kWh}$ (25\% of capacity loss due to aging). Similarly to the previous case (see section 3.4), the system represented by (29), (30), (39) and (40) is modeled in Simulink. The simulation is carried out for the same stand-alone system with the same net power profile (see Fig. 7).

The results are shown in Fig. 11 considering $S O C_{i 1}=80 \%$ and $S O C_{i 2}=30 \%$. The first graph plots the transient SOC response. Thanks to the control, both SOCs tend to reach the same value after a different initial status. Comparing this figure to Fig. 8, it can be observed that the SOC response is much faster for the curve shifting method. Furthermore, it has constant dynamics, which are determined by $\tau_{S O C 2}=6.6$ hours from (49). In the second graph, the entire one-year simulation is represented, showing a low SOC imbalance. After the initial transient, the net power causes the SOC difference to change because $C_{1} / S_{\text {rat } 1}=8 \mathrm{~h} \neq C_{2} / S_{\text {rat } 2}=6 \mathrm{~h}$, as predicted by (48). The $S O C_{1}-S O C_{2}$ difference during the one-year period, disregarding the initial transient, reaches a peak value of $-9.9 \%$, an rms value of $1.35 \%$ and an average value of $-0.02 \%$. These values are lower than for the slope changing method and can also be reduced still further if so desired by increasing $M_{S}$ yet without interacting with the power response dynamics. 

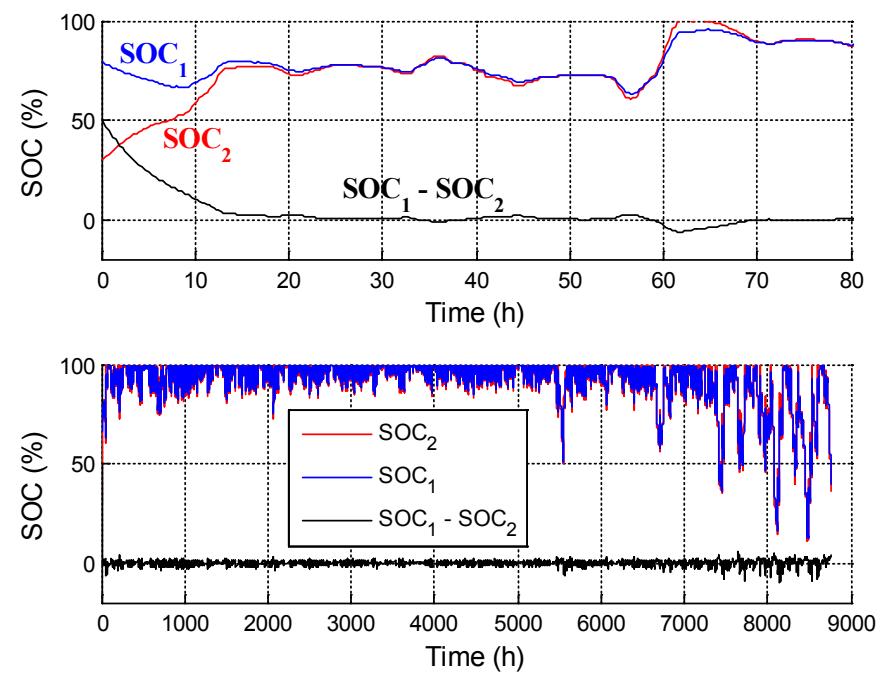

Fig. 11. SOC evolution for a stand-alone system for the curve shifting method

Another simulation is carried out in order to validate the power response for the curve shifting method. For this purpose, two batteries with their inverters as well as a number of loads are modeled with the software PSIM. The inverters are connected in parallel and generate the ac grid according to the proposed curve shifting method, with $f_{0}=50 \mathrm{~Hz}, M_{P}=0.3 \mathrm{~Hz}, M_{S}=0.3 \mathrm{~Hz}, S O C_{0}=0.8$. The features of the system were shown in Table 1, and the battery SOCs during the simulation were $S_{O C C_{I}}=0.8$ and $S \mathrm{C}_{2}=0.4$. The results for the per-unit real powers and the filtered grid frequency are shown in Fig. 12. At the beginning, only inverter 1 is connected, supplying the 4-kW load. At about second 1, inverter 2 is connected; then, at second 1.5 , a $2.7-\mathrm{kW}$ load is connected; and finally, at second 2, the same $2.7-\mathrm{kW}$ load is disconnected. It can be observed that $p_{1}$ is always higher that $p_{2}$, which helps balance the SOCs. Furthermore, since the droop coefficient $M_{P}$ is not modified, the power response is optimized for every operating point. Concerning the grid frequency, it changes due to the droop method, but its variation range is within the allowable limits for a stand-alone system.

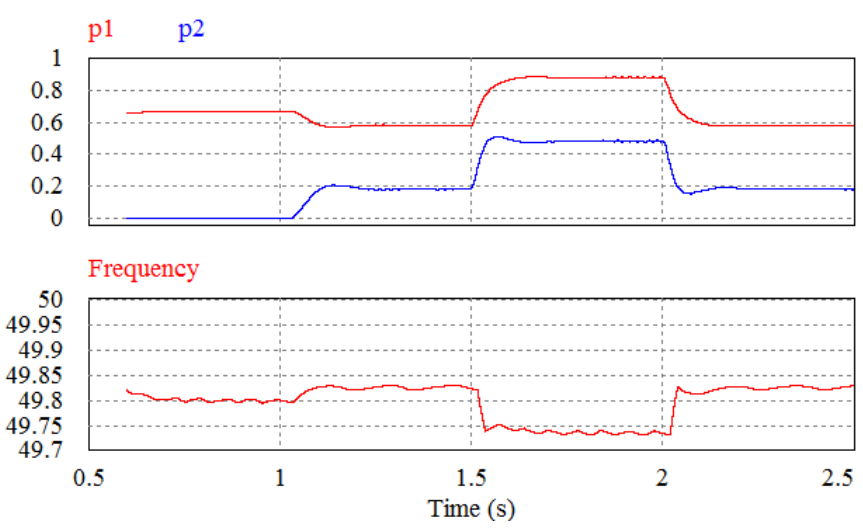

Fig. 12. Simulation results for two battery inverters in discharging mode

\section{EXPERIMENTAL RESULTS}

The proposed SOC-based droop method is now validated by experimental tests. Two batteries with their inverters are connected in parallel and create the ac grid. Their features are shown in Table 1. The battery inverter models are Ingecon Hybrid AC Link 3TL and Ingecon Hybrid AC Link 6TL. Their configuration has been modified in order to implement the proposed droop method. The used $P-f$ curve is (36) for $f_{0}=50 \mathrm{~Hz}, M_{P}=0.3 \mathrm{~Hz}, M_{S}=0.3 \mathrm{~Hz}, S O C_{0}=0.8$, as selected in section 4.4 and shown in Fig. 9. This curve is programmed in the inverter microprocessors. Each inverter measures its output power and then changes the output voltage frequency accordingly. The battery banks are made by series connection of vented lead-acid batteries, model 6 PVS 660 . The battery bank 1 is composed by 10 battery units and the battery bank 2 consists of 5 battery units. During the experiments, battery 1 has a greater charge than battery 2, with $S O C_{I}=0.8$ and $S O C_{2}=0.4$. A load bank and a PV emulator with its inverter have been 
connected to the grid. They make it possible to change their real and reactive power as desired and thus to set the desired operating point. Precision power analyzer WT1800 served to obtain the data, supplying powers and frequencies every $50 \mathrm{~ms}$. The battery inverters, battery banks, PV emulator and load bank are shown in Fig. 13.

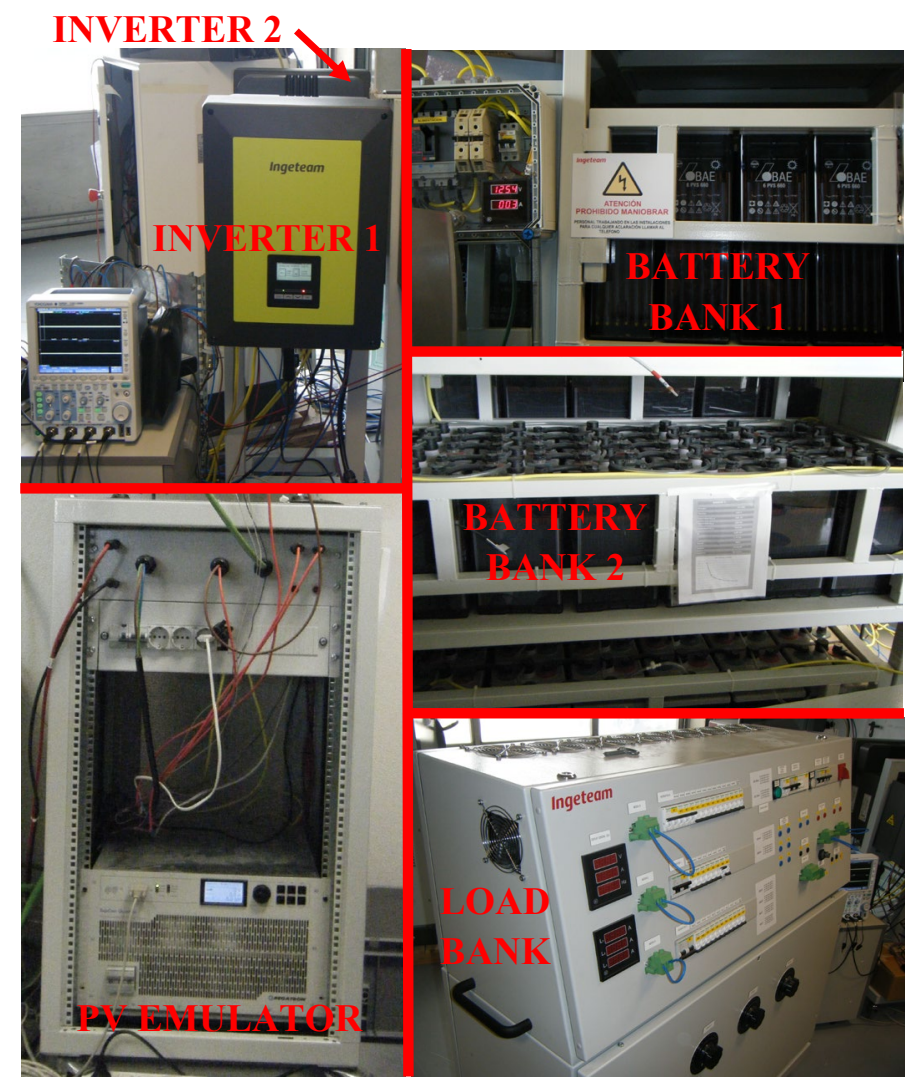

Fig. 13. PV emulator, battery banks and load bank used for the experimental setup

The first test was conducted for the battery inverters in discharging mode. The per-unit real powers and the filtered grid frequency are shown in Fig. 14. At the start, inverter 1 is operating alone, supplying a $4 \mathrm{~kW}$ load. As a result, $P_{1}=4 \mathrm{~kW}, p_{1}=0.67, P_{2}=0$, and $p_{2}=0$. Then, at second 2 , inverter 2 is connected and helps supply the load. The power distribution can now be obtained by means of (39) and (40) as $P_{1}=3.47 \mathrm{~kW}, p_{1}=0.58, P_{2}=0.53 \mathrm{~kW}$, and $p_{2}=0.18$. Then, a $2.7 \mathrm{~kW}$ load is added to the ac bus. The net power becomes $P_{T}=6.7 \mathrm{~kW}$ and the power distribution becomes $P_{l}=5.27 \mathrm{~kW}, p_{l}=0.88, P_{2}=1.43 \mathrm{~kW}$, and $p_{2}=0.48$. Finally, the $2.7 \mathrm{~kW}$ load is disconnected, and the system returns to the previous operating point. The figure shows how $p_{1}$ is always higher than $p_{2}$ thanks to the control. Since $S O C_{l}=0.8$ and $S O C_{2}=0.4$, this helps balance the SOCs. With regard to the grid frequency, this changes in line with net power variations according to (37). The figure shows that this frequency variation is moderate and totally acceptable for a stand-alone system. These experimental results are in accordance with the simulation shown in Fig. 12.

The second test is carried out for the battery inverters in charging mode. Fig. 15 shows the per-unit powers and the filtered grid frequency. Throughout the entire experiment, the photovoltaic inverter operated under MPPT and supplied $6 \mathrm{~kW}$ to the ac grid. Inverter 1 was initially connected with no load and, consequently, $P_{1}=-6 \mathrm{~kW}, p_{1}=-1, P_{2}=0$, and $p_{2}=0$. After a while, inverter 2 was connected, resulting in a different power distribution with $P_{1}=-3.2 \mathrm{~kW}, p_{1}=-0.53, P_{2}=-2.8 \mathrm{~kW}$, and $p_{2}=-0.93$. Then, at about second 5.5, a $2.7 \mathrm{~kW}$ load was connected, leading to a net power $P_{T}=-3.3 \mathrm{~kW}$. The power distribution becomes $P_{1}=-1.4 \mathrm{~kW}, p_{1}=-0.23, P_{2}=-1.9 \mathrm{~kW}$, and $p_{2}=-0.63$. The figure shows that, when both inverters are connected, $p_{1}$ is always higher than $p_{2}$. Thus, battery 2 is charged with more perunit power, which helps balance the SOCs. The grid frequency, also shown in Fig. 15, follows net power variations and its variation range is between allowable limits for a stand-alone system. It is also worth noting that, for the curve shifting method, the power response is slightly affected by the operating point. In effect, focusing on the power transients in Fig. 14 and Fig. 15, it can be noted that the rising time is similar in all cases. 

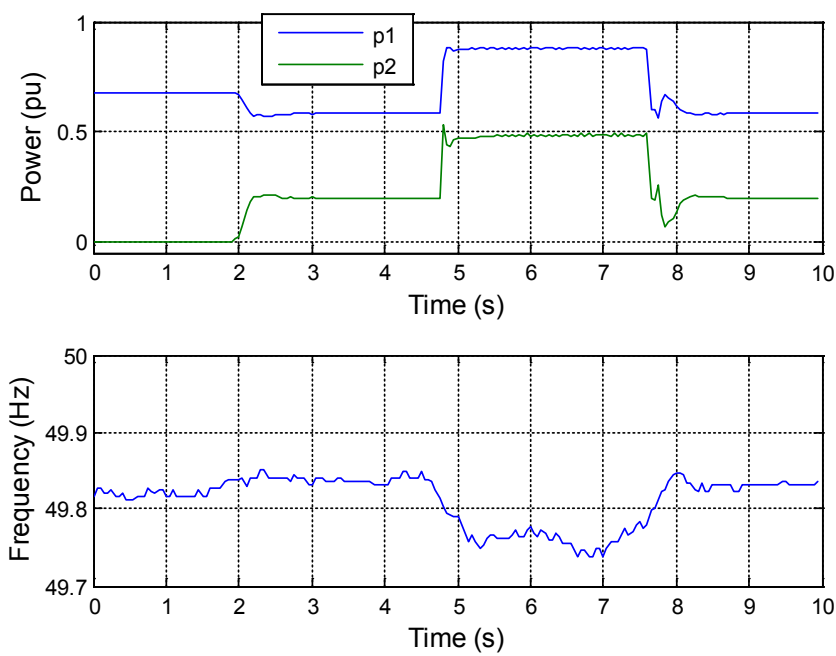

Fig. 14. Experimental results for two battery inverters in discharging mode
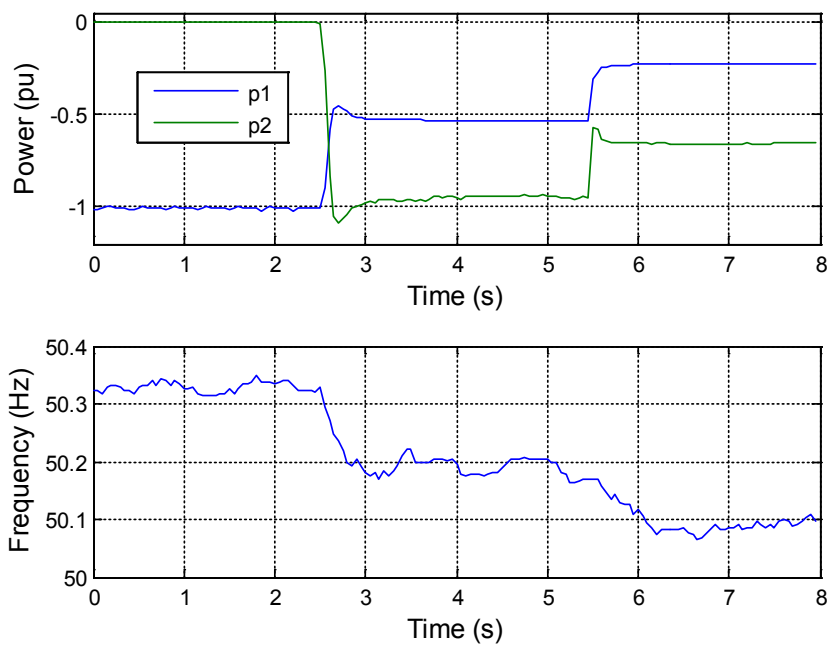

Fig. 15. Experimental results for two battery inverters in charging mode

\section{DISCUSSION}

Throughout this paper, the analytical study, the simulations and the experimental results show that the proposed curve shifting method has better properties than the existing slope changing methods. The proposed droop control was validated by means of simulations and experimental results. The first simulation represents the SOC response for a real power profile and was conducted for two-battery system with different initial SOCs and different $C / S_{\text {rat }}$ ratio. Even for these negative conditions, the results show that the SOC difference is very low during the whole year, with an rms value of $1.35 \%$ and an average value of $-0.02 \%$. Then, the second simulation and the experimental results represent the power response for the proposed method. It is shown, both for charging and discharging modes, that the battery with a higher SOC delivers more power or absorbs less power than the battery with a lower SOC, which helps balance the SOCs. Furthermore, the power response is optimized for every operating point and the grid frequency variation is always acceptable.

The proposed droop control can be applied to stand-alone ac supply systems and to ac microgrids with distributed energy storage, to balance the battery SOCs with no need of communication. The installation of distributed storage units is increasing and is expected to further expand in the future due to the need for redundancy and the development of microgrids. Two important advantages of the method with regard to existing ones are that it is based on local measurements and ensures a quick and stable power response for 
every operating point. Furthermore, its implementation is straightforward since only an independent term needs to be added to the conventional droop.

\section{CONCLUSION}

This paper presents a new SOC-based droop control method which achieves energy management for different battery inverters in stand-alone ac supply systems with distributed energy storage. The proposed technique shifts the $P-f$ curve either upwards or downwards in line with the battery SOC and, as a result, the stored energy becomes balanced with no need for communications between inverters. Thanks to the proposed SOC-based droop control, power and SOC responses are decoupled, making it possible to optimize both responses by means of the two $P-f$ curve parameters. The power response can be optimized by means of power droop coefficient $M_{P}$, in the same way as for the conventional droop method. With regard to the SOC response, it is possible to improve the transient and reduce the SOC imbalance by increasing SOC coefficient $M_{S}$.

The proposed method is compared to an existing one, the slope changing method, which modifies the $P-f$ curve slope as a function of the battery SOC. In contrast to the method proposed in this paper, the power and SOC response are not decoupled in the slope changing method, and the design parameter, $n$, must be chosen as a trade-off between both responses. Furthermore, the power response is highly dependent on the operating point, leading to slow dynamics and power errors when operating with low SOCs.

A one-year simulation was conducted for both techniques using a real power profile. The results show adequate energy management for both techniques, however the proposed method achieves better performance for both the transient response and the SOC imbalance. The experimental results for the proposed control validate the theoretical analysis for different operating points, showing how the battery with a higher SOC delivers more power or absorbs less power than the battery with a lower SOC, which helps balance the SOCs.

\section{APPENDIX}

Although the system model was developed for 2 battery inverters, the proposed technique can be generalized for an arbitrary number of $\mathrm{n}$ battery inverters. The power response modeling, developed in section 2, and the SOC response modeling for the curve shifting method, developed in section 4.3 , will be derived in this appendix for $\mathrm{n}$ battery inverters. The purpose is to obtain the transfer function poles in order to predict the transient response. The expression for the characteristic equation is thus determined, which makes it possible to disregard the independent terms, such as net power $P_{T}$, initial angle $\theta_{i}$, and initial SOC value $S O C_{i}$.

After the derivations, some examples will be provided for 4 batteries with their inverters. In these examples, the parameters presented in Table 1 (but with $C_{2}=18 \mathrm{kWh}$ due to aging) are used together with two other battery inverters. Battery inverter 3 has a rated power $S_{\text {rat } 3}=5000 \mathrm{VA}$, an output inductance $L_{3}=3 \mathrm{mH}$, and a battery capacity $C_{3}=25 \mathrm{kWh}$, and battery inverter 4 has a rated power $S_{\text {rat } 4}=4000 \mathrm{VA}$, an output inductance $L_{4}=4 \mathrm{mH}$, and a battery capacity $C_{4}=40 \mathrm{kWh}$.

\section{A. Power Response for $n$ Battery Inverters}

Rewriting (5)-(8) for $\mathrm{n}$ battery inverters leads to

$$
\begin{aligned}
& P_{i}=\frac{V E}{X_{i}} \cdot \delta_{i}, \quad \delta_{i}=I \cdot f_{i}-\theta_{V}, \quad i=1, \ldots, n \\
& \sum_{j=1}^{n} P_{j}=0 .
\end{aligned}
$$

From (A.2), one can obtain some simplified equations for the system plant as

$$
P_{1} \cdot X_{1}-P_{i} \cdot X_{i}=V E \cdot I \cdot\left(f_{1}-f_{i}\right), \quad i=2, \ldots, n .
$$


The conventional droop method changes the frequencies in order to share the power. Considering that the power sampling and measurement (transfer function $\mathrm{H}_{\mathrm{P}}$ ) is the same for every inverter, the control is expressed as follows:

$$
f_{i}=f_{0}-m_{i} \cdot H_{P} \cdot P_{i}, \quad i=1, \ldots, n .
$$

From (A.3) and (A.4), every power can be expressed as a function of $P_{l}$, i.e.

$$
P_{i}=\frac{X_{1}+V E \cdot I \cdot H_{P} \cdot m_{1}}{X_{i}+V E \cdot I \cdot H_{P} \cdot m_{i}} \cdot P_{1}, \quad i=2, \ldots, n .
$$

Introducing (A.5) into (A.2) and operating makes it possible to obtain the characteristic equation as

$$
\operatorname{den}_{P}=\sum_{k=1}^{n} \prod_{\substack{j=1 \\ j \neq k}}^{n}\left(X_{j}+V E \cdot I \cdot H_{P} \cdot m_{j}\right) .
$$

The roots of this expression correspond to the closed-loop transfer function poles for the power response. Some examples are provided in Table A.1 for different inverter configurations, where the different inverters were presented in this appendix, and the droop coefficient is $M_{P}=0.3 \mathrm{~Hz}$. It can be seen that the system has $3 \cdot(n-1)$ poles, with $(n-1)$ pairs of conjugate poles and $(n-1)$ real poles. Furthermore, the poles for configurations with different inverters are between the extreme poles for configurations with equal inverters.

TABLE A.1

CLOSED-LOOP POLES FOR THE POWER RESPONSE

\begin{tabular}{|c|c|c|}
\hline Configuration & Complex poles & Real poles \\
\hline \multirow{2}{*}{$\mathrm{N}$ times Inv1 } & $\mathrm{N}-1$ times & $\mathrm{N}-1$ times \\
& $-20.5 \pm 20.1 \mathrm{j}(\xi=0.71)$ & -142 \\
\hline \multirow{2}{*}{$\mathrm{N}$ times Inv2 } & $\mathrm{N}-1$ times & $\mathrm{N}-1$ times \\
& $-18.7 \pm 29.3 \mathrm{j}(\xi=0.54)$ & -146 \\
\hline \multirow{2}{*}{$\mathrm{N}$ times Inv3 } & $\mathrm{N}-1$ times & $\mathrm{N}-1$ times \\
& $-19.8 \pm 24.3 \mathrm{j}(\xi=0.63)$ & -144 \\
\hline \multirow{2}{*}{$\mathrm{N}$ times Inv4 } & $\mathrm{N}-1$ times & $\mathrm{N}-1$ times \\
& $-20.0 \pm 22.8 \mathrm{j}(\xi=0.66)$ & -143 \\
\hline Inv1, Inv2 & $-19.5 \pm 25.8 \mathrm{j}(\xi=0.60)$ & -144 \\
\multirow{2}{*}{ Inv1, Inv2, Inv3, Inv4 } & $-19.0 \pm 28.1 \mathrm{j}(\xi=0.56)$ & -143 \\
& $-19.9 \pm 23.5 \mathrm{j}(\xi=0.65)$ & -144 \\
& $-20.3 \pm 21.3 \mathrm{j}(\xi=0.69)$ & -145 \\
\hline
\end{tabular}

\section{B. SOC response for $n$ Battery Inverters}

Rewriting (37) and (47) for $n$ battery inverters leads to

$$
\begin{aligned}
& f_{i}=f_{0}-M_{P} \cdot P_{i} / S_{r a t, i}+M_{S} \cdot\left(S O C_{i}-S O C_{0}\right), \quad i=1, \ldots, n \\
& S O C_{i}=-\frac{P_{i}}{C_{i} \cdot S}, \quad i=1, \ldots, n .
\end{aligned}
$$

From these equations and considering that $f_{l}=f_{i}$ (for $\mathrm{i}=2, \ldots, \mathrm{n}$ ), every power can be expressed as a function of $P_{l}$, that is

$$
P_{i}=\frac{\frac{M_{P}}{M_{S}} \cdot \frac{1}{S_{r a t 1}} s+\frac{1}{C_{1}}}{\frac{M_{P}}{M_{S}} \cdot \frac{1}{S_{r a t, i}} s+\frac{1}{C_{i}}} \cdot P_{1}, \quad i=2, \ldots, n .
$$

Introducing (B.3) into (A.2) and operating makes it possible to obtain the characteristic equation as

$$
d e n_{S O C}=\sum_{k=1}^{n} \prod_{\substack{j=1 \\ j \neq k}}^{n}\left(\frac{M_{P}}{M_{S}} \cdot \frac{1}{S_{r a t, j}} \cdot s+\frac{1}{C_{j}}\right) .
$$

From this expression, the closed-loop transfer function poles for the SOC response can be obtained. Similarly to Table A.1, Table B.1 shows the time constants associated with the poles for the same previous configurations and with $M_{S}=M_{P}=0.3 \mathrm{~Hz}$. It can be seen that the system has (n-1) real poles. In 
addition, the poles for configurations with different inverters are between the extreme poles for configurations with equal inverters also in this case.

TABLE B. 1

CLOSED-LOOP TIME CONSTANTS FOR THE SOC RESPONSE

\begin{tabular}{|c|c|}
\hline Configuration & Time constant \\
\hline $\mathrm{N}$ times Inv1 & $\mathrm{N}-1$ times $\tau=8 \mathrm{~h}$ \\
\hline $\mathrm{N}$ times Inv2 & $\mathrm{N}-1$ times $\tau=6 \mathrm{~h}$ \\
\hline $\mathrm{N}$ times Inv3 & $\mathrm{N}-1$ times $\tau=5 \mathrm{~h}$ \\
\hline $\mathrm{N}$ times Inv4 & $\mathrm{N}-1$ times $\tau=10 \mathrm{~h}$ \\
\hline Inv1, Inv2 & $\tau=6.6 \mathrm{~h}$ \\
\hline Inv1, Inv2, Inv3, Inv4 & $\tau=5.4 \mathrm{~h}, 6.6 \mathrm{~h}, 9.2 \mathrm{~h}$ \\
\hline
\end{tabular}

\section{ACKNOWLEDGMENT}

This work was supported in part by the Spanish Ministry of Economy and Competitiveness under Grant DPI2013-42853-R, and by the Public University of Navarre through a doctoral scholarship.

The authors gratefully acknowledge the financial and ongoing support of INGETEAM POWER TECHNOLOGY.

\section{REFERENCES}

[1] D. P. Kaundinya, P. Balachandra, and N. H. Ravindranath, "Grid-connected versus stand-alone energy systems for decentralized power-A review of literature," Renewable and Sustainable Energy Reviews, vol. 13, pp. 2041-2050, 2009.

[2] K. Bandara, T. Sweet, and J. Ekanayake, "Photovoltaic applications for off-grid electrification using novel multi-level technology with energy storage," Renewable Energy, vol. 37, pp. 82-88, 2012.

[3] C. Olcan, "Multi-objective analytical model for optimal sizing of stand-alone photovoltaic water pumping systems," Energy Conversion and Management, vol. 100, pp. 358-369, 2015.

[4] M. C. Chandorkar, D. M. Divan, and R. Adapa, "Control of parallel connected inverters in standalone ac supply systems," IEEE Transactions on Industry Applications," vol. 29, no. 1, pp. 136-143, 1993.

[5] B. Domenech, L. Ferrer-Martí, and R. Pastor, "Including management and security of supply constraints for designing standalone electrification systems in developing countries," Renewable Energy, vol. 80, pp. 359-369, 2015.

[6] J. P. Torreglosa, P. García, L. M. Fernández, and F. Jurado, "Hierarchical energy management system for stand-alone hybrid system based on generation costs and cascade control," Energy Conversion and Management, vol. 77, pp. 514-526, 2014.

[7] L. Zhang, N. Gari, and L. V. Hmurcik, "Energy management in a microgrid with distributed energy resources," Energy Conversion and Management, vol. 78, pp. 297-305, 2014.

[8] H. Ghoddami, M. B. Delghavi, and A. Yazdani, "An integrated wind-photovoltaic-battery system with reduced powerelectronic interface and fast control for grid-tied and off-grid applications," Renewable Energy, vol. 45, pp. 128-137, 2012.

[9] F. Valenciaga, and P. F. Puleston, "Supervisor control for a stand-alone hybrid generation system using wind and photovoltaic energy," IEEE Transactions on Energy Conversion, vol. 20, no. 2, pp. 398-405, 2005.

[10] K. Strunz, E. Abbasi, and D. N. Huu, "DC microgrid for wind and solar power integration," IEEE Journal of Emerging and Selected Topics in Power Electronics, vol. 2, no. 1, pp. 115-126, 2014.

[11] A. Choudar, D. Boukhetala, S. Barkat, and J. M. Brucket, "A local energy management of a hybrid PV-storage based distributed generation for microgrids," Energy Conversion and Management, vol. 90, pp. 21-33, 2015.

[12] P. C. Loh, D. Li, Y. K. Chai, and F. Blaadjerg, "Hybrid ac-dc microgrids with energy storages and progressive energy flow tuning," IEEE Transactions on Power Electronics, vol. 28, no. 4, pp. 1533-1543, 2013.

[13] R. Kallel, G. Boukettaya, and L. Krichen, "Demand side management of household appliances in stand-alone hybrid photovoltaic system," Renewable Energy, vol. 81, pp. 123-135, 2015.

[14] M. Mehrasa, E. Pouresmaeil, H. Mehrjerdi, B. N. Jorgensen, and J. P. S. Catalao, "Control technique for enhancing the stable operation of distributed generation units within a microgrid," Energy Conversion and Management, vol. 97, pp. 362-373, 2015.

[15] A. Urtasun, P. Sanchis, I. San Martín, J. López, and L. Marroyo, "Modeling of small wind turbines based on PMSG with diode bridge for sensorless maximum power tracking," Renewable energy, vol. 55, pp. 138-149, 2013.

[16] A. Urtasun, P. Sanchis, and L. Marroyo, “Adaptive voltage control of the $\mathrm{dc} / \mathrm{dc}$ boost stage in PV converters with small input capacitor," IEEE Transactions on Power Electronics, vol. 28, no. 11, pp. 5038-5048, 2013.

[17] O. Gehrke, S. Ropenus, and P. Venne, "Distributed energy resources and control: a power system point of view," http://www.risoe.dk/rispubl/reports/ris-r-1608_248-257.pdf, 2007.

[18] Y. Ito, Y. Zhongqing, and H. Akagi, "DC microgrid based distribution power generation system," in Power Electronics and Motion Control Conference, vol. 3, pp. 1740-1745, 2004.

[19] K. Techakittiroj, S. Patumtaewapibal, V. Wongpaibool, and W. Threevithayanon, "Roadmap for implementation of dc system in future houses" in International Conference on Harmonics and Quality of Power (ICHQP), pp. 1-5, 2008. 
[20] O. Haas, O. Ausburg, and P. Palensky, "Communication with and within distributed energy resources," in International Conference on Industrial Informatics, pp 352-356, 2006.

[21] N. Rezaei, M. Kalantar, "Economic-environmental hierarchical frequency management of a droop-controlled islanded microgrid," Energy Conversion and Management, vol. 88, pp. 498-515, 2014.

[22] E. A. A. Coelho, P. C. Cortizo, and P. F. D. Garcia, "Small-signal stability for parallel-connected inverters in stand-alone ac supply systems," IEEE Transations on Industry Applications, vol. 38, pp. 533-542, 2002.

[23] A. Mohd, E. Ortjohann, D. Morton, and O. Omari, "Review of control techniques for inverters parallel operation," Electric Power Systems Research, vol. 80, pp. 1477-1487, 2010.

[24] N. Rezaei, M. Kalantar, "Smart microgrid hierarchical frequency control ancillary service provision based on virtual inertia concept: An integrated demand response and droop controlled distributed generation framework," Energy Conversion and Management, vol. 92, pp. 287-301, 2015.

[25] E. Serban and H. Serban, "A control strategy for a distributed power generation microgrid application with voltage- and current-controlled source converter," IEEE Transations on Power Electronics, vol. 25, pp. 2981-2992, 2010.

[26] J. M. Guerrero, J. C. Vasquez, J. Matas, L. G. de Vicuña, and M. Castilla, "Hierarchical control of droop-controlled ac and dc microgrids- A general approach toward standarization," IEEE Transactions on Industrial Electronics, vol. 58, pp. 158-172, 2011.

[27] A. Urtasun, P. Sanchis, D. Barricarte, and L. Marroyo, "Energy management strategy for a battery-diesel stand-alone system with distributed PV generation based on grid frequency modulation," Renewable Energy, vol. 66, pp. 325-336, 2014.

[28] K. O. Oureilidis, C. S. Demoulias, "Microgrid wireless energy management with energy storage system," in International Universities Power Engineering Conference (UPEC), pp. 1-6, 2012.

[29] R. Majumber, B. Chaudhuri, A. Ghosh, R. Majumber, G. Ledwich, and F. Zare, "Improvement of stability and load sharing in an autonomous microgrid using supplementary droop control loop," IEEE Transaction on Power Systems, vol. 25, no. 2, pp. 796-808, 2010.

[30] I. U. Nutkani, P. C. Loh, and F. Blaadjerg, "Droop scheme with consideration of operating costs," IEEE Transactions on Power Electronics, vol. 29, no. 3, pp. 1047-1052, 2014.

[31] H. Kakigano, Y. Miura, and T. Ise, "Distribution voltage control for de microgrids using fuzzy control and gain-scheduling technique," IEEE Transactions on Power Electronics, vol. 28, no. 5, pp. 2246-2258, 2013.

[32] C. Li, T. Dragicevic, N. L. Diaz, J. C. Vasquez, and J. M. Guerrero, "Voltage scheduling droop control for state-of- charge balance of distributed energy storage in dc microgrids," in IEEE International Energy Conference (ENERGYCON), pp. 13101314, 2014.

[33] X. Lu, K. Sun, J. M. Guerrero, and L. Huang, "SoC-based dynamic power sharing method with ac-bus voltage restauration for microgrid applications," in Annual Conference on IEEE Industrial Electronics Society (IECON), pp. 5677-5682, 2012.

[34] X. Lu, K. Sun, J. M. Guerrero, J. C. Vasquez, L. Huang, and R. Teodorescu, "SoC-based droop method for distributed energy storage in dc microgrid applications," in IEEE International Symposium on Industrial Electronics (ISIE), pp. 1640-1645, 2012.

[35] J. M. Guerrero, J. C. Vasquez, J. Matas, M. Castilla, and L. G. de Vicuña, "Control strategy for flexible microgrid based on parallel line-interactive UPS systems," IEEE Transations on Industrial Electronics, vol. 56, no. 3, pp. 726-736, 2009.

[36] T. Dragicevic, J. M. Guerrero, J. C. Vasquez, and D. Skrlec, "Supervisory control of an adaptive-droop regulated dc microgrid with battery management capability," IEEE Transactions on Power Electronics, vol. 29, no. 2, pp. 695-706, 2014.

[37] X. Lu, K. Sun, J. M. Guerrero, J. C. Vasquez, and L. Huang, "Double quadrant state-of-charge-based droop control method for distributed energy storage systems in autonomous dc microgrids," IEEE Transactions on Smart Grid, vol. 6, no. 1, pp. 147$157,2015$.

[38] X. Lu, K. Sun, J. M. Guerrero, J. C. Vasquez, and L. Huang, "State-of-charge balance using adaptive droop control for distributed energy storage systems in dc microgrid applications," IEEE Transactions on Industrial Electronics, vol. 61, no. 6, pp. 2804-2815, 2014.

[39] E. Barklund, N. Pogaku, M. Prodanovic, C. Hernandez-Aramburu, and T. C. Green, "Energy management in autonomous microgrid using stability-constrained droop control of inverters," IEEE Transactions on Power Electronics, vol. 23, pp. 23462352, 2008.

[40] R. B. Godoy, J. O. P. Pinto, C. A. Canesin, E. A. A. Coelho, and A. M. A. C. Pinto, "Differential-evolution-based optimization of the dynamic response for parallel operation of inverters with no controller interconnection," IEEE Transactions on Industrial Electronics, vol. 59, pp. 2859-2866, 2012.

[41] A. R. Bergen, Power Systems Analysis. Englewood Cliffs, NJ: Prentice Hall, 1986.

[42] T. W. Li, and C. Kao, "An accurate power control strategy for power-electronics-interfaced distributed generation units operating in a low-voltage multibus microgrid," IEEE Transactions on Power Electronics, vol. 24, no. 12, pp. 2977-2988, 2009.

[43] C. T. Lee, C. C. Chu, P. T. Cheng, "A new droop control method for the autonomous operation of distributed energy resource interface converters," IEEE Transactions on Power Electronics, vol. 28, no. 4, pp. 1980-1993, 2013.

[44] J. He, Y. W. Li, J. M. Guerrero, F. Blaadjerg, and J. C. Vasquez, “An islanding microgrid power sharing approach using enhanced virtual impedance control scheme," IEEE Transactions on Power Electronics, vol. 28, no. 11, pp. 5272-5282, 2013.

[45] J. Hu, J. Zhu, D. G. Dorrell, and J. M. Guerrero, "Virtual flux droop method - A new control strategy of inverters in microgrids," IEEE Transactions on Power Electronics, vol. 29, no. 9, pp. 4704-4711, 2014.

[46] N. Pogaku, M. Prodanovic, and T. C. Green, "Inverter-based microgrids: small-signal modelling and testing," in International Conference on Power Electronics, Machines and Drives, pp. 499-504, 2006.

[47] W. Peng, and Y. Baghzouz, "Accurate circuit model for steady-state and dynamic performance of lead-acid AGM batteries," in International Conference and Utility Exhibition (ICUE), pp. 1-6, 2011.

[48] Y. Tang, W. Yuan, M. Pan, and Z. Wan, "Experimental investigation on the dynamic performance of a hybrid PEM fuel cell/battery system for lightwight electric vehicle application,” Applied Energy, vol. 88, no. 1, pp. 68-76, 2011. 
[49] Y. Chen, S. Lin, and B. Hong, "Experimental study on a passive fuel cell/battery hybrid power system," Energies, vol. 6, no. 12, pp. 6413-6422, 2013.

[50] J. M. Guerrero, J. Matas, L. G. de Vicuña, M. Castilla, and J. Miret, "Decentralized control for parallel operation of distributed generation inverters using resistive output impedance," IEEE Transactions on Industrial Electronics, vol. 54, no. 2, pp. 9941004, 2007.

[51] E. A. A. Coelho, P. C. Cortizo, and P. F. D. Garcia, "Small signal stability for single phasae inverter connnected to stiff ac system," in IEEE Industry Applications Conference, no. 4, pp. 2180-2187, 1999.

[52] M. Gao, S. Yang, C. Jin, Z. Ren, M. Chen, and Z. Qian, "Analysis and experimental validation for power calculation based on $p-q$ theory in single-phase wireless-parallel inverters," in Applied Power Electronics Conference and Exposition (APEC), pp. 620-624, 2011.

[53] J. L. Agorreta, M. Borrega, J. López, and L. Marroyo, "Modeling and control of N-paralleled grid-connected inverters with LCL filter coupled due to grid impedance in PV plants," IEEE Transactions on Power Electronics, vol. 26, no. 3, pp. 770-785, 2011.

[54] K. Ng, Y. Huang, C. Moo, and Y. Hsieh, "An enhanced coulomb counting method for estimating state-of-charge and state-ofhealth of lead-acid batteries," in International Telecommunications Energy Conference (INTELEC), pp. 1-5, 2009.

[55] T. Markvart, A. Fragaki, J. N. Ross, "PV system sizing using observed time series of solar radiation,” Solar Energy, vol. 80, no. 1, pp. 46-50, 2006. 